\title{
The GITEWS ocean bottom sensor packages
}

\author{
O. Boebel ${ }^{1}$, M. Busack ${ }^{2}$, E. R. Flueh ${ }^{3}$, V. Gouretski ${ }^{1, *}$, H. Rohr ${ }^{2}$, A. Macrander ${ }^{1}$, A. Krabbenhoeft ${ }^{3}$, M. Motz ${ }^{4}$, and \\ T. Radtke ${ }^{4}$ \\ ${ }^{1}$ Alfred Wegener Institute for Polar and Marine Research, Bussestr. 24, 27570 Bremerhaven, Germany \\ ${ }^{2}$ OPTIMARE Sensorsysteme AG, Am Luneort 15a, 27572 Bremerhaven, Germany \\ ${ }^{3}$ IFM-GEOMAR, Leibniz Institute for Marine Sciences, Wischhofstr. 1-3, 24148 Kiel, Germany \\ ${ }^{4}$ develogic GmbH, Eiffestr. 598, 20537 Hamburg, Germany \\ *now at: Institut für Meereskunde, Bundesstr. 53, 20146 Hamburg, Germany
}

Received: 7 April 2010 - Revised: 19 July 2010 - Accepted: 28 July 2010 - Published: 31 August 2010

\begin{abstract}
The German-Indonesian Tsunami Early Warning System (GITEWS) aims at reducing the risks posed by events such as the 26 December 2004 Indian Ocean tsunami. To minimize the lead time for tsunami alerts, to avoid false alarms, and to accurately predict tsunami wave heights, realtime observations of ocean bottom pressure from the deep ocean are required. As part of the GITEWS infrastructure, the parallel development of two ocean bottom sensor packages, PACT (Pressure based Acoustically Coupled Tsunameter) and OBU (Ocean Bottom Unit), was initiated. The sensor package requirements included bidirectional acoustic links between the bottom sensor packages and the hosting surface buoys, which are moored nearby. Furthermore, compatibility between these sensor systems and the overall GITEWS data-flow structure and command hierarchy was mandatory. While PACT aims at providing highly reliable, long term bottom pressure data only, OBU is based on ocean bottom seismometers to concurrently record sea-floor motion, necessitating highest data rates. This paper presents the technical design of PACT, OBU and the HydroAcoustic Modem (HAM.node) which is used by both systems, along with first results from instrument deployments off Indonesia.
\end{abstract}

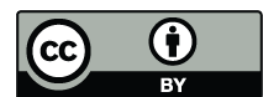

Correspondence to: O. Boebel (olaf.boebel@awi.de)

\section{Introduction}

After the 26 December 2004 Indian Ocean tsunami, the development of the German-Indonesian Tsunami Early Warning System was initiated (Rudloff et al., 2009). To provide tsunami alerts as quickly and precisely as possible, GITEWS pursues a multi-sensor approach in combination with a high resolution, predictive modelling component. Arguably, the fastest data channel is provided by land-based seismometers (Hanka et al., 2010) and GPS instruments, which measure horizontal and vertical tectonic movements from which (earthquake) source models are derived. These, in turn, are used to select pre-calculated numerical ocean models, which provide detailed tsunami inundation predictions. However, not every earthquake causes a tsunami, nor is every tsunami caused by an earthquake. To improve quantitative inundation predictions and to also protect against tsunamis caused by landslides, direct oceanic sea-level measurements offer a second in-situ data channel (faster than $10 \mathrm{~min}$ ), though at slower response times than achieved by the land-based instruments $(<5 \mathrm{~min})$. Overall, GITEWS aims at providing reliable warning bulletins within at least $10 \mathrm{~min}$ of the earthquake (Behrens et al., 2010).

The provision of such infrastructure is the task of the GITEWS work package 2000 "Ocean Instrumentation"1. It

\footnotetext{
${ }^{1}$ The GITEWS work package "Ocean instrumentation" comprises the following sub-work packages relevant to the projects described herein: "Coordination" (Konsortium Deutsche Meeresforschung, KDM); "GPS surface buoy" (Deutsches GeoForschungsZentrum, GFZ); "PACT" (AWI); "OBU" (IFMGEOMAR); "Maintenance buoys" (GFZ). The handling of PACT and OBU data, once on land, is subject of the working groups "Decision Support System" (DLR) and "System Integration" (Deutsches GeoForschungsZentrum, GFZ).
} 


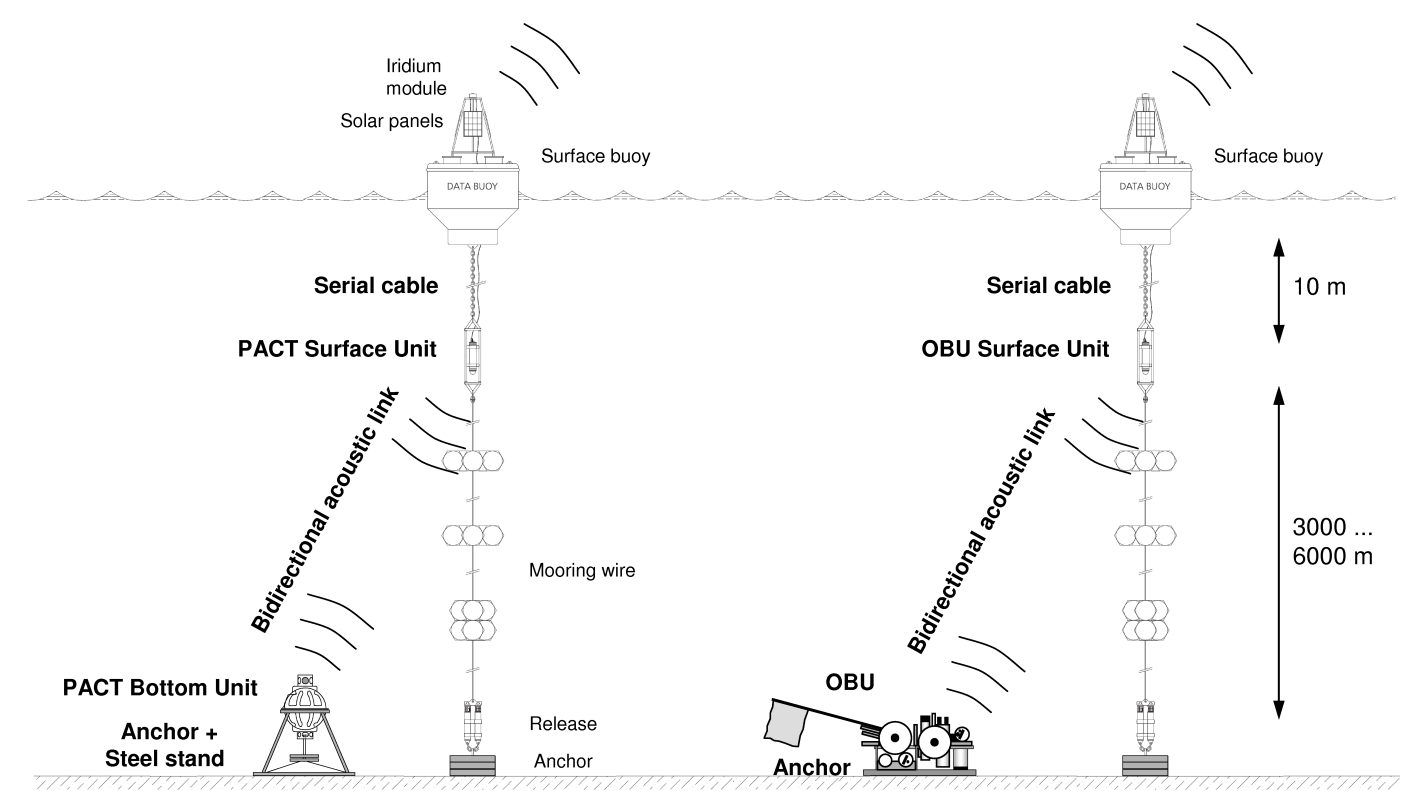

Fig. 1. Sketch of the PACT (left) and OBU (right) bottom sensor packages together with their hosting surface buoy moorings. Note that figure elements are not to scale.

aims for data reliability and redundancy by deploying a suite of instruments based on quite diverse measurement techniques, which - amongst other parameters - capture the sealevel both at the coast on islands off Indonesia (tide gauges), and offshore in the deep ocean using bottom pressure gauges and seismic data.

Two independent projects have been commissioned in GITEWS to provide in-situ, real-time data from the seafloor: PACT, a custom designed, highly integrated and costefficient bottom sensor package collecting bottom pressure data, and OBU, which collects bottom pressure and seismic data employing off-the-shelf instruments which are mechanically integrated into a single platform.

Both PACT and OBU represent the far outpost of the GITEWS data acquisition system. Designed as autonomous, free-fall landers, these systems' bottom units (BU) are placed on the sea-floor in the immediate vicinity of hosting surface buoys (Fig. 1), which are provided by the GeoForschungsZentrum Potsdam, GFZ (Schöne et al., 2008, 2010). A bidirectional communication channel is established between each $\mathrm{BU}$ and its hosting buoy by means of a pair of hydroacoustic modems. For PACT and OBU, the hosting surface buoys serve as data relay stations, providing a satellite communication link to the GITEWS Decision Support System (DSS) in the Early Warning and Mitigation Centre (EWMC) in Jakarta. With the GFZ surface buoys being also the host to multiple additional sensors (GPS, weather, buoy acceleration) and systems (energy management, communication links), PACT and OBU data streams had to be integrated with the overall data flow and control architecture as implemented on the surface buoy's onboard computer.
GITEWS operates under the presumption that in most instances, the land-based seismic array will provide the first indication of a possible tsunami. Rather than wait for a BU to automatically detect the tsunami wave, GITEWS prioritizes a top-down approach as soon as any sensor indicates an anomaly. In this case, all available relevant sensors (or sensor groups) would be toggled to temporally high-resolution capturing tsunami mode via a single remote command from the EWMC. This switching of temporal sensor resolution between a low capturing normal mode (active most of the time) and a high capturing tsunami mode is a necessary consequence of the energetic constraints of autonomously operating off-shore instrumentation.

Unavoidably, each entering of a capturing tsunami mode, results in a competition of the various sensors for energy and communication bandwidth, which requires careful balancing of available resources. These external requirements necessitated the implementation of complex, hierarchical communication protocols, which, in the projects described herein, are implemented through specific software modules, PACT-daemon (pactd) and OBU-daemon (obud), respectively. Hence, the PACT and OBU systems comprise the following components:

- Bottom unit (BU): data acquisition, automated detection of pressure anomalies, acoustic telemetry of data telegrams, acoustic reception of commands;

- Surface unit (SU): acoustic reception and buffering of telegrams, acoustic telemetry of commands;

- pactd/obud: management of data and command flow between the SU and the host buoy's computer. 


\begin{tabular}{|c|c|c|}
\hline BU-controller composes message & submits message to BU-modem & $\stackrel{\partial}{m}$ \\
\hline \multicolumn{2}{|c|}{ RS 232 with $\uparrow$ hardware handshake } & $\stackrel{1}{0}$ \\
\hline \multicolumn{2}{|c|}{ BU-modem composes telegram, splits telegram into packets, and transmits packets } & $\alpha$ \\
\hline \multicolumn{2}{|c|}{ hydroacoustic transmission $\mathfrak{q}$ with handshake } & \multirow{3}{*}{ 它๖ } \\
\hline SU-modem receives packets, reconstructs telegra & nd informs PACT-daemon of telegram availability & \\
\hline \multicolumn{2}{|c|}{ underwater cable RS $232 \downarrow$ with hardware handshake } & \\
\hline $\begin{array}{r}\text { PACT-daemon retrieves message, saves message in } \\
\text { availability } c\end{array}$ & $\begin{array}{l}\text { cated directory and informs buoy-demon of message } \\
\text { unami alert }\end{array}$ & \multirow{3}{*}{ 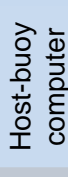 } \\
\hline IP based point to & oint communication & \\
\hline \multicolumn{2}{|c|}{ Buoy-daemon arranges for transfer of message to Upload Area (FTP) } & \\
\hline Satellite Link, TCP/IP & Satellite Link, TCP/IP & \\
\hline $\begin{array}{l}\text { PACT-Postprocessor recalculates sea level heights } \\
\text { and anomalies (time correction, barometric correction, } \\
\text { recalculate anomalies) }\end{array}$ & $\begin{array}{c}\text { Command and Control Demon (CoCod) commands } \\
\text { the buoy-daemon }\end{array}$ & \multirow{4}{*}{$\sum_{\Psi}^{0}$} \\
\hline Messages via Joint Management System (JMS) & Commands via Web Services Descript. Language & \\
\hline \multicolumn{2}{|c|}{ Integration platform Tsunami Service Bus (TSB) } & \\
\hline Messages via Sensor Alert / Web Notification Serv. & Commands via Sensor Planning Service & \\
\hline
\end{tabular}

Fig. 2. Schematic of data flow of PACT system. Messages are transferred top-down, i.e. originate at the PACT-BU (top level) and terminate at the data support system (DSS) of the tsunami early warning centre (TEWC). Commands may be issued in the TEWC and are transferred bottom-up to the PACT-BU, where they might toggle the BU's state. All communication links are secured via handshake protocols.

Additional software and hardware modules, developed independently of this workpackage, complete the data transfer to the EWMC and the data management, display and evaluation there (Fleischer et al., 2010). A similar architecture applies for the return route, i.e. the transfer of commands issued at the EWMC to the BU (Fig. 2).

At the time of initiation of these projects, three issues were identified as most critical to a successful integration of ocean bottom sensors into the GITEWS sensor system: 1) The availability of an energetically efficient hydroacoustic modem that allows long distance and/or high data rate communication; 2) The implementation of an enduring electromechanical integration of the surface modem in the surface buoy mooring, and 3) the unknown effect of the ambient soundscape including mooring induced noise and rain on the success rate of acoustic transmissions, particularly from the bottom to the surface modem. Possible problems with data acquisition and instrument deployment and recovery were initially thought to be less likely, as instrument designs were based on existing hardware or components, but turned out as (remediable) weak spots later in the project.

The geographic locations of the planned GITEWS moorings (Fig. 3), were optimized for minimal alert delays using tsunami scenarios numerically modelled at AWI (Behrens, 2008). PACT was chosen to occupy five of the ten proposed surface buoy sites (Sumatra 1-4) and Java 1, including the deepest locations, while three OBUs shall be distributed among the remaining sites.

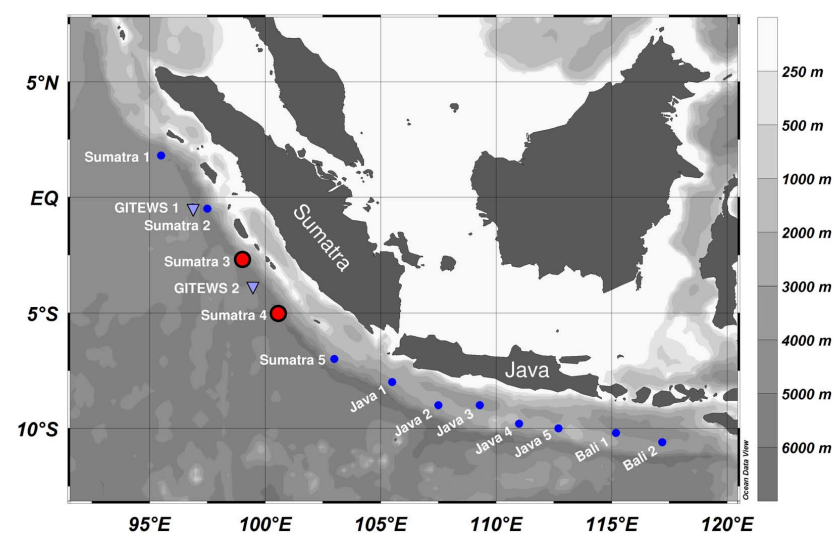

Fig. 3. Proposed (and partially occupied) GITEWS mooring deployment positions off Indonesia. Triangles mark two test moorings deployed in 2005. In April 2009, surface buoys were deployed at Sumatra 1-5 and Java 1-5 (blue dots). Red dots indicate the two positions where PACT already provided bottom pressure data.

This paper describes in detail the technology and operating modes of the PACT and OBU bottom and surface units and their respective daemons along with results from initial deployments. The paper commences with the technical details and performance of the HAM.node modems, which provide the vital acoustic link between the bottom sensor packages and the hosting surface buoy. It then continues to describe 

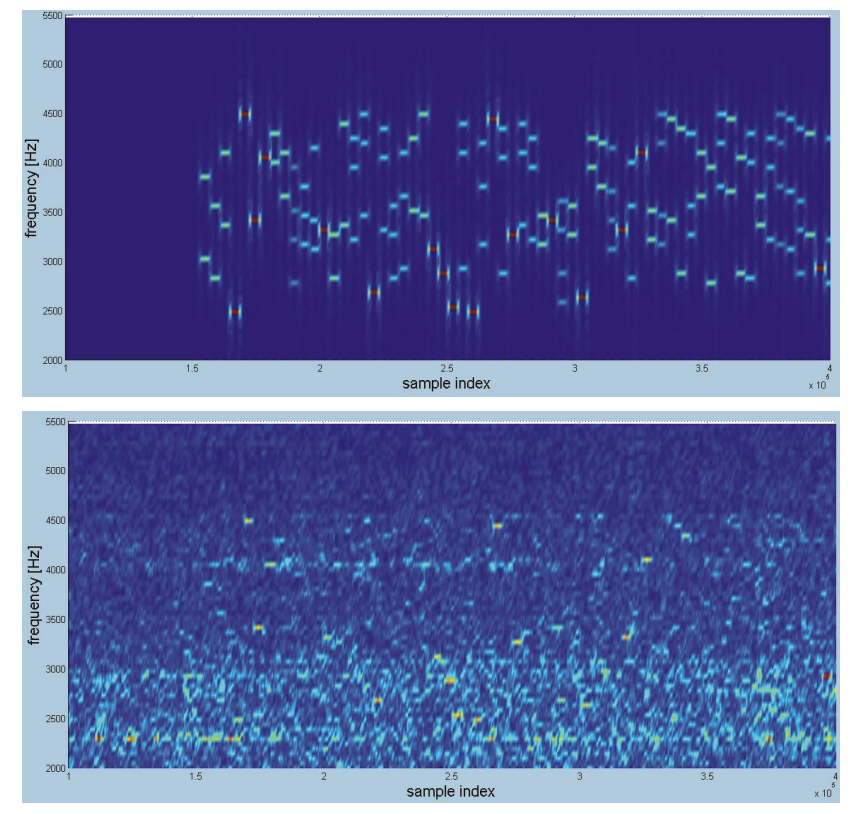

Fig. 4. Spectrograms of transmitted (electrical output, top) and received (acoustic in-water, bottom) signals of a of HAM.node modem in incoherent frequency shift keying (hopping n-of-m-FSK) modulation mode. The record was taken in 2007 during tests in the Bergen Fjord across at least $500 \mathrm{~m}$ of horizontal transmission distance with the transmitter at $20 \mathrm{~m}$ and the receiver at $10 \mathrm{~m}$ depth. The $\mathrm{x}$-axis shows sample number (linearly related to time), the $\mathrm{y}$ axis the signal frequency in $\mathrm{Hz}$. Colour indicates spectral intensity (blue $=$ low to red $=$ high).

the design of PACT and results from the first deployments of five systems in Indonesia before proceeding with a description of the design of the OBU and its first results, before giving a brief outlook of planned activities.

\section{HAM.node acoustic modems}

\subsection{General description}

The HAM.node (Hydro Acoustic Modem with network capabilities) was selected on the basis of its flexible modular approach and transmission protocols, which provide communication and high level system management functionality for a wide range of subsea data acquisition systems. With GITEWS featuring two possible bottom sensor packages, PACT and OBU, it seemed particularly appealing to maintain the flexibility of using either of these at any hosting surface buoy, necessitating the use of compatible modems which preferably could remotely be tuned to the sensor package option selected. However, at project start, HAM.node modems were at a prototype stage and modem developments continued throughout and as part of the PACT and OBU workpackages with particular attention to the specific requirements of these applications. HAM.node modems are now com-

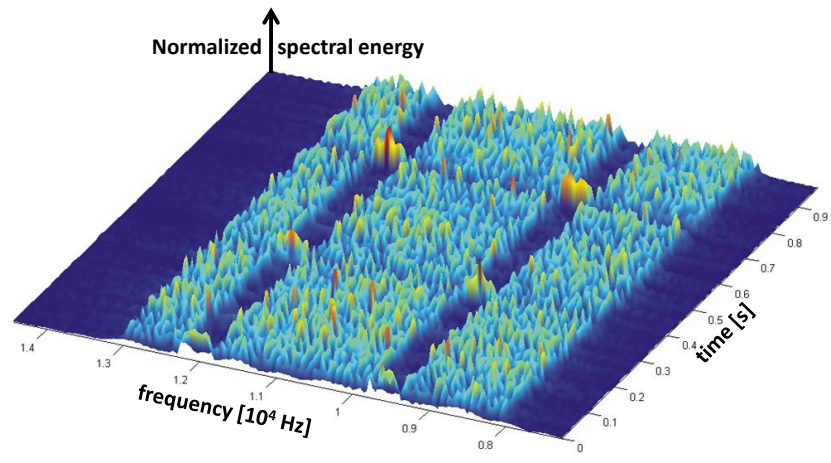

Fig. 5. Spectrogram of transmitted (electrical output) signals of a HAM.node modem in coherent DPSK (differential phase shift keying) OFDM (orthogonal frequency division multiplex modulation) mode for communication in near vertical channels.

mercially available from develogic $\mathrm{GmbH}$ since 2008 (see www.develogic.de for further details).

Within GITEWS, the HAM.node modems are used in two different communication modes (high reliability/low speed versus high speed/high power). Besides communication services, the modems also provide customizable, application specific functionality to expand the functionality of standard, off-the-shelf instruments. The OBU implementation for example makes use of this feature: tsunami detection algorithms and seismic data access are integrated into the modems firmware which executes GITEWS specific commands on the seismic data recorder.

\subsection{Modulation, coding and transmission scheme}

The HAM.node operating software implements a multilayer system interconnection model similar to the OSI (Open Systems Interconnection) reference model (International Telecommunication Union, 1998). The uppermost layer is represented by the user and application interface receiving commands and data from a host, whereas the lowest layer is the hardware interface layer handling the signal transmission and reception via the system's high voltage transmit power amplifier and the receive amplifier with adjustable gain interfacing to an acoustic transducer through a transmit/receive-switch.

Data coding and modulation algorithms are implemented on a floating point digital signal processor (DSP). The system provides two different configurable modulations schemes, which both incorporate algorithms for Doppler correction for relative motion up to $10 \mathrm{~ms}^{-1}$.

An incoherent frequency hopping n-of-m FSK (frequency shift keying) modulation scheme (Fig. 4) is used for transmissions through acoustic channels with complex characteristics (e.g. shallow water, long range) or for small data volumes when the link reliability has the highest priority, as for PACT. Alternatively, a non coherent m-DPSK (differential phase-shift keying) modulation scheme (Fig. 5) is 


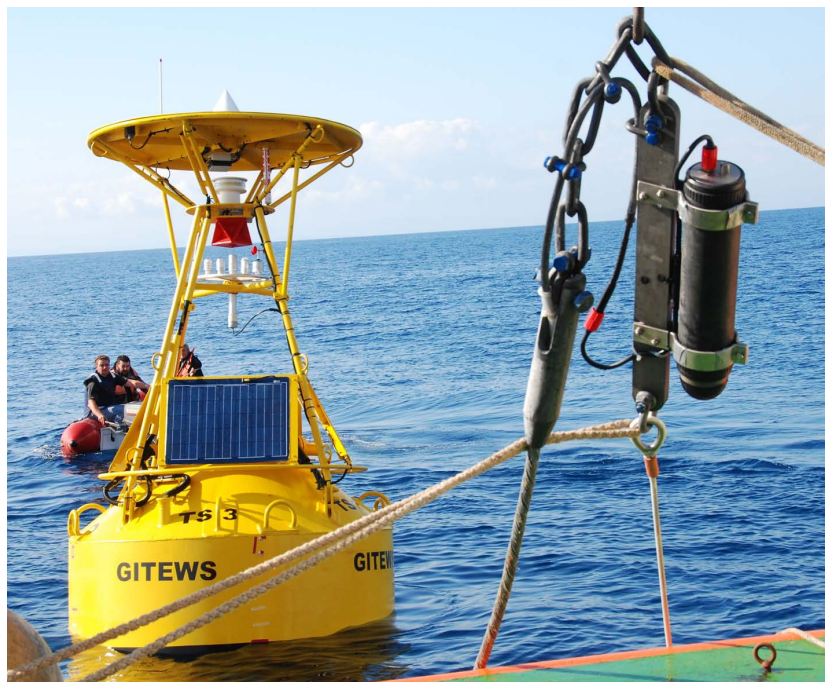

Fig. 6. HAM.node modem (dark cylinder, right) and hosting surface buoy (yellow, left) during tests in the Mediterranean offshore Toulon. The HAM.node modem is attached to a steel girdle in-line with the mooring line.

suitable for transmissions in vertical or near vertical channels with limited amounts of multi-path-propagation, when high data throughputs are required. With the OBU units requiring the transmission of large amounts (typically $50 \mathrm{kB}$ to $500 \mathrm{kB}$ ) of seismic data, m-DPSK was selected for those units.

The data link layer implements convolutional forward error correction (Shu Lin and Costello, 2004), data compression and checksum verification. A fractionally spaced decision feedback equalizer (Benvenuto and Cherubini, 2002) can optionally be enabled for more complex channels when using m-DPSK to partially compensate the time variable properties of the acoustic channel.

CRC (cyclic redundancy check) checksums based handshaking and automatic data packet retransmission between bottom and surface modems ensure that each message is received without any bit errors.

\subsection{The HAM.node modem as used in GITEWS surface moorings}

To reduce acoustic disturbance from wind waves and air bubbles, the modems (Fig. 6) are mounted approximately $10 \mathrm{~m}$ below the sea-surface to a stainless steel girder integrated in the hosting surface buoy's mooring line. (Based on at-sea experience, this depth seemed to best balance improved acoustic conditions and increasing cable costs with increasing depth while avoiding the need for long guard intervals during DPSK transmissions in response to late surface echoes. Due to the near vertical communication axis, thermocline effects showed negligible influence on the transmission loss, as confirmed through sound propagation modelling.) The modems are housed in a corrosion-resistant shallow water composite cylinder with a depth rating of $750 \mathrm{~m}$ and are connected electrically to the hosting buoy by a reinforced underwater cable. Powered periodically from the hosting buoy, the modem is equipped with a set of rechargeable batteries (nominal voltage of $25.2 \mathrm{~V}$ ) to buffer peak power demands during acoustic communication. Modems produced in 2009 (for both PACT and OBU) are equipped with NiMH LR20 Acculoop 8.5 Ah cells (providing $214 \mathrm{Wh}$ total), with low self-discharge. These battery packs were substituted by $\mathrm{NiCd}$ cells (5.1 Ah each, providing $129 \mathrm{Wh}$ total) for PACT modems produced in 2010. These cells are less susceptible to damage due to deep discharging, which appeared to have occurred when the umbilical cord between the hosting surface buoy and the modem broke, causing unrecoverable damage to the NiMH cells used in modems deployed 2009.

\subsection{The HAM.node modem as PACT surface unit}

The HAM.node modems as used in the PACT-SU transmit in the $9-12.8 \mathrm{kHz}$ carrier band and are equipped with omnidirectional transducers. In the PACT bottom unit, the HAM-node is integrated as OEM (Original Equipment Manufacturer) module in the PACT-BU's Vitrovex glass pressure housing.

For communication along the near-vertical direction between PACT BU and SU, n-m-FSK modulation is used. The operation profile of PACT's HAM.node modems is optimized for a highly reliable, yet energy-efficient transmission of moderate amounts of data (about 100 Byte per message). At a data rate of $200 \mathrm{bps}$, each message takes a few seconds for transmission; if necessary, transmission attempts are repeated up to 3 times at intervals of about $25 \mathrm{~s}$.

This repetition cycle represents a balance between data efficiency and conservation of energy under the following assumption: If an acoustic transmission is obstructed by short term noise (e.g. rattling of a shackle), a second or third attempt some tens of seconds later, is likely to result in a successful transmission. However, if increased ambient noise prevails for longer periods (i.e. due to rain or passing of a ship), the likelihood of successful transmission decreases in the short term. In this case additional transmission attempts are unlikely to significantly increase the transmission success rate, but merely would drain the batteries of the BU.

At Sumatra 3 and 4, the respective PACT-BUs entered the capturing normal mode as scheduled and transmitted status messages every $4 \mathrm{~h}$ for several weeks (cf. Sect. 3.6.1). Monitoring the reliability of data transmissions during the first few days revealed the occasional drop-out of some status messages. Remote adjustment of the sensitivity threshold setting of the PACT-SU solved this problem by permitting the processing of telegrams of lesser signal amplitudes. (Initially this setting had been selected higher to reduce the possibility of ambient noise causing acoustic modem wakeups and ensuing unwanted battery drain). 
Table 1. PACT-BU deployment depths [m according to pressure record], acoustic power settings [\%], nominal source level (SL), estimated transmission loss (TL) and received levels (RL, all levels in $\mathrm{dB}_{\mathrm{rms}}$ re. $1 \mu \mathrm{Pa}$ ). Success rates are given according to: a 22 April to $12 \mathrm{May}$ (137 of 140 status messages plus 30 of 32 tsunami messages after initial modem adjustment and before cable problems of hosting surface buoy); ${ }^{\mathrm{b}} 22$ April to 2 May (57 of 59 status messages after initial modem adjustment and before surface buoy failure) .

\begin{tabular}{ccccccc}
\hline Location & Depth & Power & SL & TL & RL & Success [\%] \\
\hline Sumatra 3 & $5655 \mathrm{~m}$ & $90 \%$ & $184 \mathrm{~dB}$ & $75 \mathrm{~dB}$ & $109 \mathrm{~dB}$ & $98 \% \mathrm{a}$ \\
Sumatra 4 & $5975 \mathrm{~m}$ & $90 \%$ & $185 \mathrm{~dB}$ & $76 \mathrm{~dB}$ & $109 \mathrm{~dB}$ & $97 \%{ }^{\mathrm{b}}$ \\
\hline
\end{tabular}

After this adjustment, transmissions proved highly reliable, with $98 \%$ (135 of 138 status and tsunami messages) and $97 \%$ (57 of 59 status messages) of all messages received at locations Sumatra 3 and Sumatra 4, respectively (Table 1). This is particularly noteworthy, as these sites represent the deepest locations within the GITEWS array $(5655 \mathrm{~m}$ and $5975 \mathrm{~m}$ ), emphasizing the robustness of the acoustic transmission scheme as selected for PACT.

\subsection{The HAM.node as OBU surface unit}

The OBU surface unit is similar to the PACT surface unit, except for the installed acoustic transducer. Instead of the aforementioned omnidirectional transducer, a model with directional characteristic $\left(-3 \mathrm{~dB} @+/-35^{\circ}\right)$ and a carrier band from $11.2 \mathrm{kHz}$ to $19.2 \mathrm{kHz}$ is installed here to optimize transmission performance.

In the bottom unit, the HAM.node modem is housed in a composite deep water housing with a depth rating of $6000 \mathrm{~m}$ and is connected via SubConn underwater connectors to the seismic data recorder and external battery housings.

During extensive system tests in the Mediterranean offshore Toulon at a water depth of about $2400 \mathrm{~m}$, continuous bottom pressure data measurements and frequent seismic data recordings were transmitted to the hosting buoy. The configuration and especially the output power setting were selected as to reflect conditions to be expected in Indonesia.

The transmission success (Fig. 7) reveals nominal system operation from 8 October 2008 to 24 November 2008 with 4 transmissions per day. On 7 November, the transmission schedule was reconfigured to 12 data transmissions daily. Of a total of 338 triggered transmission sequences, only 4 failed. Reliability during that test period was better than $98.8 \%$ despite several periods of severe weather, which resulted in increased ambient conditions. By the end of November, the power supply of the OBUs bottom unit was depleted, terminating any further data transmissions.

In addition, low level logging information recorded by the acoustic modems was evaluated in order to gain experience about bit error rates during changing environmental noise due to weather conditions and bypassing vessels as well as at different transmission distances due to the changing position of the buoy. Resulting from this evaluation, the maxi-

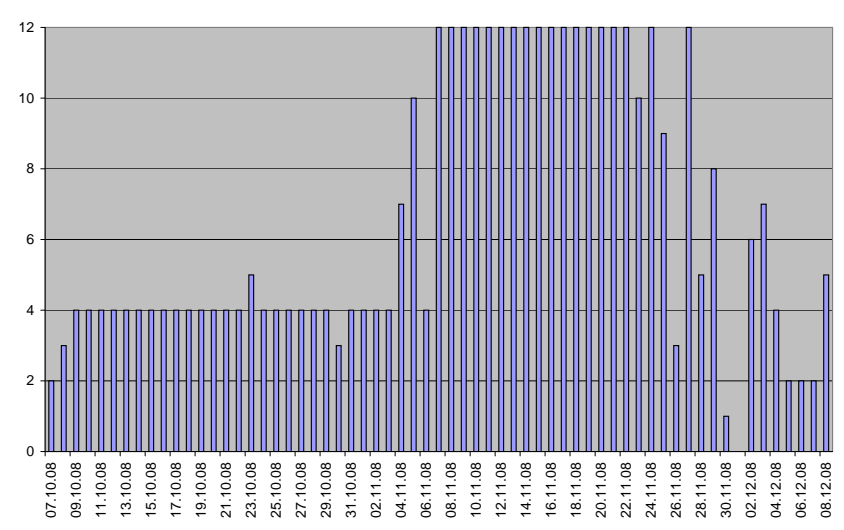

Fig. 7. Number of successfully received transmissions of initially 4, later 12 initiated transmissions per day (plus additional manually triggered transmissions). Energy supply problems of the OBU-BU lead to decreasing success after 1 December.

mum reliable transmission range with the tested OBU system based on $90 \%$ transmission success was calculated to approximately $8000 \mathrm{~m}$.

Recent tests (November 2009) offshore San Diego with a similar HAM.node setup confirmed this value as a conservative estimate. A diagonal range of $7600 \mathrm{~m}$ between a bottom system at $4000 \mathrm{~m}$ and a modem suspended from a surface vessel could be achieved. As the angle between the systems was well beyond the $-3 \mathrm{~dB}$ angle of the transducer characteristics and the surface vessel emitted additional noise which would not occur with a surface buoy, it is a safe assumption, that the maximum diagonal range of systems deployed at $6000 \mathrm{~m}$ will be at least similar. 


\section{PACT $^{2}$}

\subsection{General description}

To detect the approach of a tsunami as early as possible, sea level recordings taken in the deep ocean far off the coast are indispensible. At water depths of thousands of meters, however, a tsunami wave is only some centimetres to decimetres high and approximately one hundred kilometres long while travelling at several hundred $\mathrm{km} / \mathrm{h}$. Being able to reliably and precisely detect these slight changes in sea level requires the use of high-precision bottom pressure sensors. Installed on the seafloor, these instruments register the weight of the water column above and are able to detect passing tsunami waves due to the corresponding change in water height and hence weight. However, with this information being recorded at the seafloor, a communication link needs to be established to relay the data to the EWMC ashore in quasi real-time.

Such a system provides the DART ${ }^{\circledR}$ (Deep-ocean Assessment and Reporting of Tsunamis) buoys (Meinig et al., 2005, 2007; Mofjeld, 1997), which have been developed and operated by the US NOAA for the past decade. DART ${ }^{\circledR}$ bottom sensor packages record ocean bottom pressure, perform onboard tsunami detection and acoustically relay the data to the surface buoy. PACT employs a similar data acquisition and relaying approach; however, for its integration into the GITEWS data system several adaptations and a customized solution were needed (primarily concerning data flow control and command structure). In addition, employing the latest advances in computational power and communication technologies, PACT (Pressure based, Acoustically Coupled Tsunameter) integrates the entire sea-floor package (pressure gauge, data logger and analyzer, acoustic modem, acoustic release and relocation aids) into a single unit, i.e. a standard borosilicate glass sphere rated for a deployment depth of $6000 \mathrm{~m}$. The design of PACT thereby pursues a set of goals considered particularly attractive in the context of minimizing logistic demands for the long-term maintenance of such a system, i.e. to (1) minimize the deployment and recovery effort, (2) maximize deployment intervals, (3) minimize investment and maintenance costs, and (4) maximize data reliability and hardware robustness. Specifically, PACT was designed to make the system deployable and recoverable from small ships and even helicopters, to realize deployment intervals of at least 2 years, to restrict investment costs per system to less than $50000 €$ and to achieve a system uptime of $>99 \%$ (a maximum of one lost status message per month).

\footnotetext{
${ }^{2}$ PACT was developed under the auspices of the Alfred Wegener Institute (AWI) in collaboration with two German small and medium-sized enterprises, SMEs, (OPTIMARE Sensorsysteme AG and develogic $\mathrm{GmbH}$ ), the MARUM - Zentrum für Marine Umweltwissenschaften der Universität Bremen, and the Graduate School of Oceanography (University of Rhode Island, USA)
}

Similar to DART ${ }^{\circledR}$, PACT monitors ocean bottom pressure, automatically detects pressure anomalies possibly caused by tsunamis, and transmits the data in near realtime from the sea floor to the hosting surface buoy. This is achieved by two sub-systems (Fig. 1): The bottom unit, PACT-BU, is a free falling lander, which rests at the seafloor (OPTIMARE Sensorsysteme AG, 2008). It continuously measures bottom pressure and performs onboard tsunami detection. The data are transmitted via a bidirectional acoustic link to the surface unit (PACT-SU) (develogic $\mathrm{GmbH}, 2008$ ). The PACT-SU is located at a depth of about $10 \mathrm{~m}$ below the hosting GITEWS surface buoy (Schöne et al., 2010) and is attached to the latter by an underwater communication and power cable. Communication between the PACT-SU and the host buoy's computer is facilitated by the PACT-daemon software, which is installed on the host buoy's computer. Any data received from the PACT-BU are saved on the buoy and eventually relayed by the surface buoy via satellite to the EWMC, where the entire set of GITEWS observations and modelled tsunami scenarios are processed (Fleischer et al., 2010).

The bi-directional communication link also offers the option of remotely changing detection thresholds and other parameters without the need to recover the system from the seafloor, which helps to fine-tune a system to its specific deployment location while deployed.

\subsection{Data flow, command, and control}

The PACT system (i.e. PACT-BU, PACT-SU and PACTdaemon) operates in six different modes (Fig. 8), which are either activated through the BU's internal program or remotely through the EWMC. Four of these operating modes mirror the EWMC's overall system modes which apply to the entire suite of GITEWS sensors, while two additional modes are specific to PACT for instrument deployment and recovery.

Capturing normal mode is the default mode during instrument operation. Pressure is averaged over and polled every $15 \mathrm{~s}$. Every $4 \mathrm{~h}$, a status message containing a set of 2410 -min pressure averages of the last $4 \mathrm{~h}$ is generated and transmitted to the surface unit. The status message also contains engineering data (battery voltages, tilt and internal pressure), time stamp and message ID which permit monitoring and forecasting the operational state of the bottom unit. Capturing normal mode is entered whenever the $\mathrm{BU}$ is reset (command "1" in Fig. 8), or automatically, when a capturing tsunami mode (see below) has expired. Status messages are not forwarded immediately upon their reception by the buoy, but in combination with status information from the buoy's other sensors at externally determined times.

Capturing tsunami mode is triggered automatically when the tsunami detection algorithm detects two successive 15 -s pressure readings exceeding a pre-set anomaly threshold (set to $30 \mathrm{~mm}$, see Sect. 3.3). Upon entering this mode, a 


\section{PACT Operating Mode and Command Diagram}

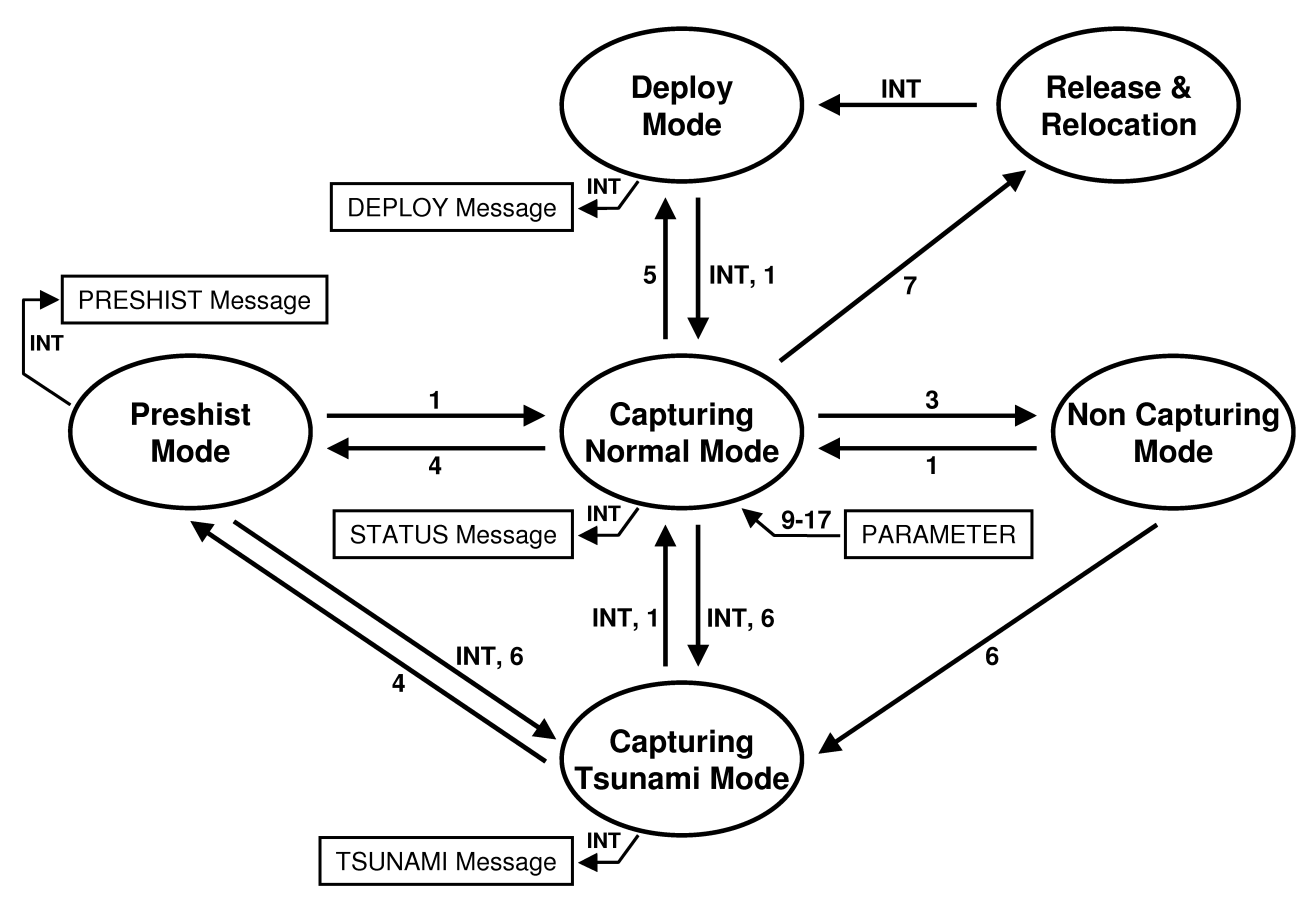

Fig. 8. PACT operating modes and command structure. Ellipses symbolize the six operating modes. Arrows indicate possible transitions between these modes, which may be initiated either by external commands \# 1, 3, 4, 5, 6 and 7, or internally via firmware control (INT). Rectangles indicate the four messages types that are generated by the firmware and a set of parameters with may be uploaded to the PACT-BU via commands 9-17.

first tsunami message is immediately issued with subsequent messages following every $2 \mathrm{~min}$. After $30 \mathrm{~min}$, the PACT-BU automatically returns to capturing normal mode. The capturing tsunami mode can also be commanded manually from the EWMC, allowing the detection of smaller tsunamis not exceeding the pre-set anomaly threshold. For the duration of the capturing tsunami mode the internal, automatic tsunami detection algorithm is deactivated, regardless of how the capturing tsunami mode initially had been triggered (manually or automatically). However, a capturing tsunami mode may be re-triggered, immediately after the system's return to capturing normal mode if the actual pressure readings still depart from the predicted pressure by more than the anomaly threshold.

A peculiarity of the GITEWS system is the fact, that at any time, mode-control and data transmission control was prescribed to be top-down. The concept is that any sensor only sends an "alarm" bit to the EWMC, which then responds by toggling relevant sensor groups (seismic, GPS, gauges, buoys) to "capturing tsunami mode". This way communication bandwidth (and costs) should be kept low during standard monitoring times and optimized during alert times (e.g. not using satellite bandwidth from sensors located out of relevant range). For PACT, this concept would have implied that PACT could enter the "capturing tsunami mode" only once it hydroacoustically transmitted the "alarm" bit to the hosting buoy, the buoy forwarded the "alarm" bit via satellite to the EWMC, the EWMC commanded the buoy via satellite to enter "capturing tsunami mode" and finally the buoy commanded - again via hydroacoustic link - the PACT-BU to assume "capturing tsunami mode". While such an approach might prove robust for instruments relying on satellite/cable communication only, the possibly significant latency time in underwater communication renders this approach unsuitable for PACT.

The PACT system circumnavigates these incompatibilities through the following approach. An automatic tsunami detection as registered by the PACT-BU, sets the PACT-BU to capturing tsunami mode and immediately transmits the first tsunami message. This message, as any other tsunami message, contains a tsunami alert flag which is extracted by the PACT-daemon and forwarded to the hosting buoy's buoydaemon, which in turn forwards it to the EWMC. Meanwhile the PACT-BU continues to transmit further tsunami messages every $2 \mathrm{~min}$ as scheduled. The PACT-daemon receives these and saves them on the hosting computer's hard disk, however without notifying the buoy-daemon of their presence.

If the EWMC reacted to the alert flag by issuing a capturing tsunami mode command to the hosting buoy (which sets the entire hosting buoy to capturing tsunami mode including 
the PACT-daemon and all other additional sensors), the PACT-daemon responds by notifying the buoy-daemon of all available tsunami messages it had meanwhile received and saved to hard disk. In turn these will then be forwarded by the buoy-daemon to the EWMC. Alternatively, if the EWMC does not respond by issuing capturing tsunami mode, after 30 min the PACT-BU will automatically return to capturing normal mode, while any saved tsunami message will be discarded as part of the routing housekeeping activities of the buoy computer.

The non capturing mode is a "sleep mode" to be used when the instrument is being transported or stored to avoid unintended activation of the acoustic modem which may result in rapid battery depletion. While deployed, it may be used to set the BU to sleep in case that extended off-line periods are to be expected for the hosting surface buoy.

Pressure history mode allows downloading of fullresolution 15-s data sets of the last $3 \mathrm{~h}$. However, the tsunami detection algorithm remains active at all times and switches the PACT-BU unit into capturing tsunami mode if required. Note that the PACT-BU's pressure history mode is not yet supported (and hence cannot be activated remotely) by the current general GITEWS specification, but it can be accessed manually via acoustic commands during servicing, e.g. from a research vessel.

Two additional modes are implemented for operational purposes during deployment and recovery only:

During deploy mode pressure and tilt information are sent at pre-defined regular intervals in deploy messages to monitor the PACT-BU's descent to the sea-floor and its orientation once landed. The deploy mode times out automatically after a customizable period (currently set to $5 \mathrm{~h}$ ) after being triggered. The currently implemented transmission schedule is optimized to monitor the deployment process, transmitting every $5 \mathrm{~min}$ for the first hour, every $10 \mathrm{~min}$ for the second and third hour, and every $20 \mathrm{~min}$ for the fourth and fifth hour. Thereafter the PACT-BU switches to capturing normal mode.

The release and relocation mode can only be triggered by commands directly entered to an acoustic surface modem. When received, the PACT-BU activates the burn-wire release and transmits deploy messages in accordance with the deploy mode schedule as described above. At the surface, a flashlight and the VHF (very high frequency) transmitter aid relocation of the system once surfaced. In instruments of version 2010, the relocation module is activated not only upon reception of the release command, but automatically whenever the instrument turns upside down, i.e. when floating up to the surface due to accidental loss of the anchor weight (see Sect. 3.4).

Last but not least, the system permits to remotely reconfigure the measurement schedule, averaging and polynomial extrapolation parameters, and tsunami detection thresholds via specific commands ("9"-“"17" in Fig. 8) without prior recovery of the PACT bottom unit.

\subsection{Data acquisition and automatic tsunami detection}

The automatic detection of a tsunami event is performed identical to the proven DART ${ }^{\circledR}$ tsunami detection algorithm as published (Meinig et al., 2005, 2007; Mofjeld, 1997). The basic concept is to compare the actual pressure $h_{k}$ (at time $=$ $t_{0}$ ), as measured every $15 \mathrm{~s}$, with a predicted pressure $H_{f}$ as based on a polynomial extrapolation of the preceding pressure records (Fig. 9). The predicted pressure for the next timestep $\left(t_{0}+15 \mathrm{~s}\right)$ is thus given by:

$H_{f}=w(1) H(1)+w(2) H(2)+w(3) H(3)+w(4) H(4)$

The weight factors $w(1)-w(4)$ are based on Newton's formula for forward extrapolation, while the four 10-min pressure averages $H(1)-H(4)$ (called nodes hereinafter) are calculated across the intervals $\left[t_{0}-190 \mathrm{~min}: t_{0}-180 \mathrm{~min}\right]$, $\left[t_{0}-130 \mathrm{~min}: t_{0}-120 \mathrm{~min}\right],\left[t_{0}-70 \mathrm{~min}: t_{0}-60 \mathrm{~min}\right],\left[t_{0}-\right.$ 10 min : $\left.t_{0}\right]$. The prediction $H_{f}$ is re-evaluated by the PACTBU every $15 \mathrm{~s}$ for each new pressure measurement and compared with the actual pressure $h_{k}$.

This approach exploits the fact that in the deep ocean, short surface waves (wind waves) have no influence on ocean bottom pressure - only long gravity waves like tides and tsunamis with wave-lengths of hundreds of kilometres affect the bottom pressure. For tides, the predicted pressure closely matches the real pressure due to their long timescales of several hours. In contrast, tsunami waves have timescales of tens of minutes and hence may be recognized by larger anomalies between prediction and observations.

The PACT-BU enters a capturing tsunami mode when the two most recent 15 -s observations both exceed a pressure anomaly $h_{k}-H_{f}$ threshold of $30 \mathrm{~mm}$ (Fig. 9). Furthermore, an additional spike criterion has to be passed, which serves to exclude false measurements. For this, the pressure reading at $t_{0}-15 \mathrm{~s}$ reading must not depart more than $100 \mathrm{~mm}$ from the mean of the pressure readings at $t_{0}$ and $t_{0}-30 \mathrm{~s}$, i.e. the pressure change should be reasonably "smooth" during the $45 \mathrm{~s}$ prior to the current measurement.

Upon entering the capturing tsunami mode, a tsunami message is immediately generated and transmitted to the surface unit. This message contains the 8 most recent pressure measurement $h_{k}$ covering the last $2 \mathrm{~min}$, and the corresponding pressure anomalies $\left(h_{k}-H_{f}\right)$. In the first tsunami message, the two most recent pressure anomalies necessarily have to be larger than the $30 \mathrm{~mm}$ threshold. Further, a timestamp (provided by the BU controller), a tsunami message ID (starting with " 0 "), and the nodes of the last undisturbed polynomial (i.e. as calculated when the event was triggered) are transmitted with the first and every following tsunami message. This message format ensures that (a) the exact start time of the event, and (b) the exact shape of the wave can reliably be determined, which is important to assess the hazard potential of the tsunami with highest possible accuracy. In case that the first tsunami message is lost (e.g. due to satellite communication error), the start time and the shape of the 


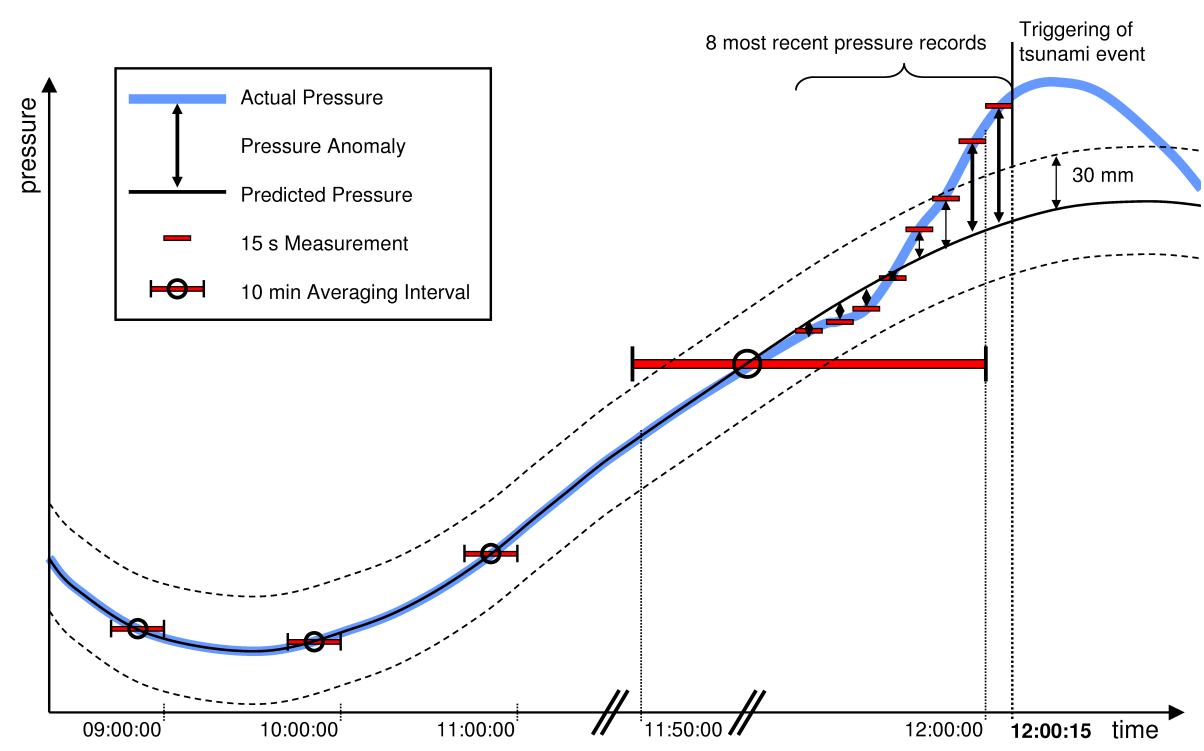

Fig. 9. Sketch illustrating the tsunami detection algorithm (Mofjeld, 1997). The solid curves show the actual (heavy blue line) and predicted (thinner black line) pressures based on four 10-min averages (horizontal bars). Note that the time axis is not to scale, zooming into the last $10 \mathrm{~min}$ and $2 \mathrm{~min}$ intervals. In this example, the two most recent 15-s records (horizontal short red bars) starting at 11:59:45 exceed the $30 \mathrm{~mm}$ anomaly threshold (dashed lines), triggering the tsunami mode at 12:00:15.

ongoing wave can be reconstructed using any tsunami message's ID, its pressure data and the included information on the nodes for cubic polynomial extrapolation (as determined at the time of entering the capturing tsunami mode). This information is included redundantly in all tsunami messages which are transmitted in 2-min intervals for $30 \mathrm{~min}$. The inclusion of information on the nodes is particularly important when the capturing tsunami mode is triggered remotely by the EMWC, as they contain the information on the recent pressure history, which is needed to correct the real-time pressure signals for tidal contributions.

The response of the PACT-BU to simulated tsunami events (Fig. 10) and the subsequent processing of PACT tsunami messages have been simulated at AWI and GFZ to ensure that the data provided by PACT are compatible with the GITEWS data flow specifications. To simulate the activities of a PACTBU, high resolution synthetic pressure data (black line in Fig. 10) were generated using real bottom pressure data measured by the PACT-BU deployed at Sumatra3. Then, a numerically modelled tsunami anomaly signal from the TsunAWI model (Babeyko et al., 2010; Harig et al., 2008) was added (heavy blue line in Fig. 10). Finally, these data were fed into the PACT-BU's internal data processing scheme, resulting in status messages and a set of 16 simulated tsunami messages once the automatic tsunami detection algorithm indicated the detection of the tsunami. These messages contain absolute pressure (red line in Fig. 10a), the "frozen" polynomial nodes ("+" signs in Fig. 10a), and pressure anomalies as based on the recent polynomial nodes (red line in Fig. 10b) and correct relative timing.
To obtain realistic estimates of time series of tsunami wave heights, however, the polynomial nodes as calculated just prior to the arrival of the tsunami should be used as depicted in Fig. 10. Predicted anomalies (Fig. 10b, cyan line) and "real" wave height (heavy blue line) coincide well during the first $30 \mathrm{~min}$. A later calculation of polynomial nodes including pressure data from after the time of arrival will, by contrast, include pressure data already influenced by the passing tsunami wave, rather than the tide only. Hence the resulting polynom will "include" part of the tsunami wave, resulting in reduced anomaly estimates (i.e. pressure data - polynominal prediction).

Over the course of several hours the "frozen" polynomial prediction (Fig. 10a cyan) unavoidably starts to diverge from the true tidal curve (Fig. 10a black), hence resulting in increasingly false estimates of tsunami anomalies (Fig. 10b cyan). However, as only the first $20 \mathrm{~min}$ of a time series are relevant in the context of GITEWS, this error remains negligible here for any practical purpose.

Both, time of arrival and anomaly time series are planned to be included in the selection of the most appropriate premodelled tsunami scenario (Behrens et al., 2010). The current implementation of the selection algorithm in fact does not use bottom pressure data, as these instruments have not yet been operational in GITEWS. However, similar to other gauge measurements (see Behrens et al., 2010, their Table 2), it is planned to use bottom pressure data together with additional data (i.e. seismic, GPS, and land based sealevel gauges) sources to select the set of most appropriate tsunami scenarios. As time progresses, this selection process 

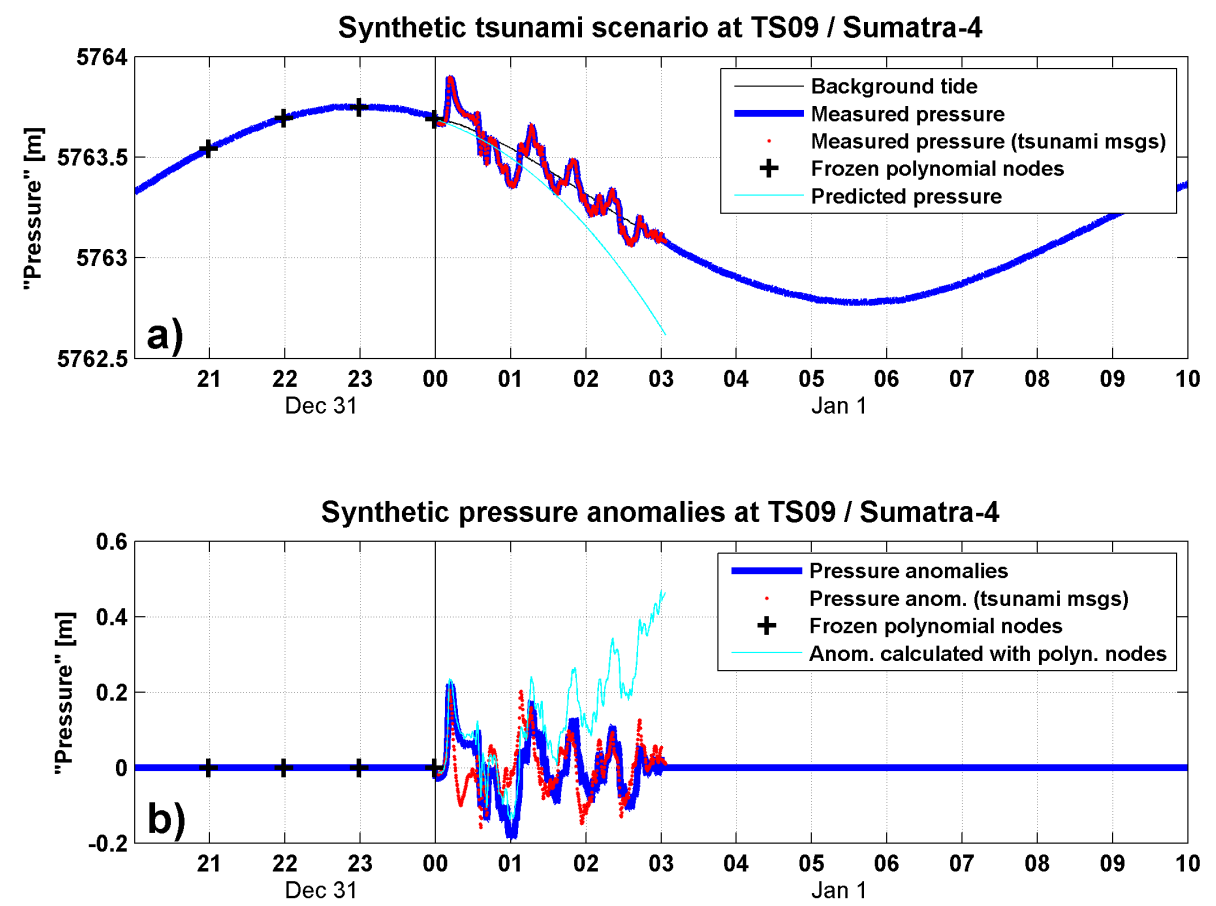

Fig. 10. Example of a synthetic tsunami scenario. Start time of the event is 1 January 00:00 (vertical line). (a) Absolute pressure. Blue: Compounded, high-resolution absolute pressure data (observed tidal signal and instrument noise combined with modelled tsunami anomaly). Red: As above, data segment to be transmitted in high-res in capturing tsunami mode. Crosses: "Frozen" polynomial nodes as calculated onboard PACT-BU. Cyan: cubic extrapolation of expected "tsunami-free" tidal curve. (b) Pressure anomalies with tides subtracted. Blue: "real" tsunami anomaly (from TsunAWI model). Red: Pressure anomalies transmitted in tsunami messages (using recent, disturbed polynomial nodes). Cyan: Pressure anomalies calculated from actual pressure and pressure prediction based on "frozen" polynomial nodes. For further explanations see text body.

Table 2. Summary locations, associated equipment, and confirmed system endurance. ${ }^{\mathrm{a}}$ Data from ship's echosounder. ${ }^{\mathrm{b}}$ Data on basis of PACT-BU pressure measurements.

\begin{tabular}{lcccccc}
\hline Location & BU S/N & Buoy ID & Deployment date & Depth & BU endurance & Likely cause of failure \\
\hline Sumatra 2 & $\# 4$ & TS 07 & 12 Apr 2009 & $\begin{array}{c}5370 \mathrm{~m}^{\mathrm{a}} \\
5377 \mathrm{dbar}^{\mathrm{b}}\end{array}$ & $1.5 \mathrm{~h}$ & Drop weight loss \& internal short-circuit \\
& & & & & \\
Sumatra 1 & $\# 6$ & TS 06 & 13 Apr 2009 & $5000 \mathrm{~m}^{\mathrm{a}}$ & 0 & Probably internal short-circuit \\
Sumatra 3 & $\# 8$ & TS 04 & 16 Apr 2009 & $\begin{array}{c}5660 \mathrm{~m}^{\mathrm{a}} \\
5655 \mathrm{~m}^{\mathrm{b}}\end{array}$ & $\begin{array}{l}37 \text { days } \\
5990 \mathrm{~m}^{\mathrm{a}}\end{array}$ & Break in underwater cable SU to buoy \\
Sumatra 4 & $\# 2$ & TS 09 & 17 Apr 2009 & Communication loss with surface buoy \\
Java 1 & $\# 7$ & TS 10 & 22 Apr 2009 & $3300 \mathrm{~m}^{\mathrm{a}}$ & $12 \mathrm{~min}$ & Drop weight loss \\
\hline
\end{tabular}

is continuously updated, always including the latest information from the full suite of active sensors.

To assign the exact timing of a tsunami event independent of any delays in the transmission chain, the PACT BU timestamps each tsunami message. However, due to the BU's internal clock drift, this timestamp needs correction. This is performed at the EWMC by comparing the BU time stamps of each message with the surface buoy's GPS time (see Fig. 2), which is assigned to each message when saving the data. The drift of the BU can then be established from the linear relationship between BU-times and GPS times. While the drift is applied to datasets as used by EWMC and prior to using the data in the selection of most appropriate models, the PACT-BU's clock itself remains uncorrected to avoid compromising system stability. 


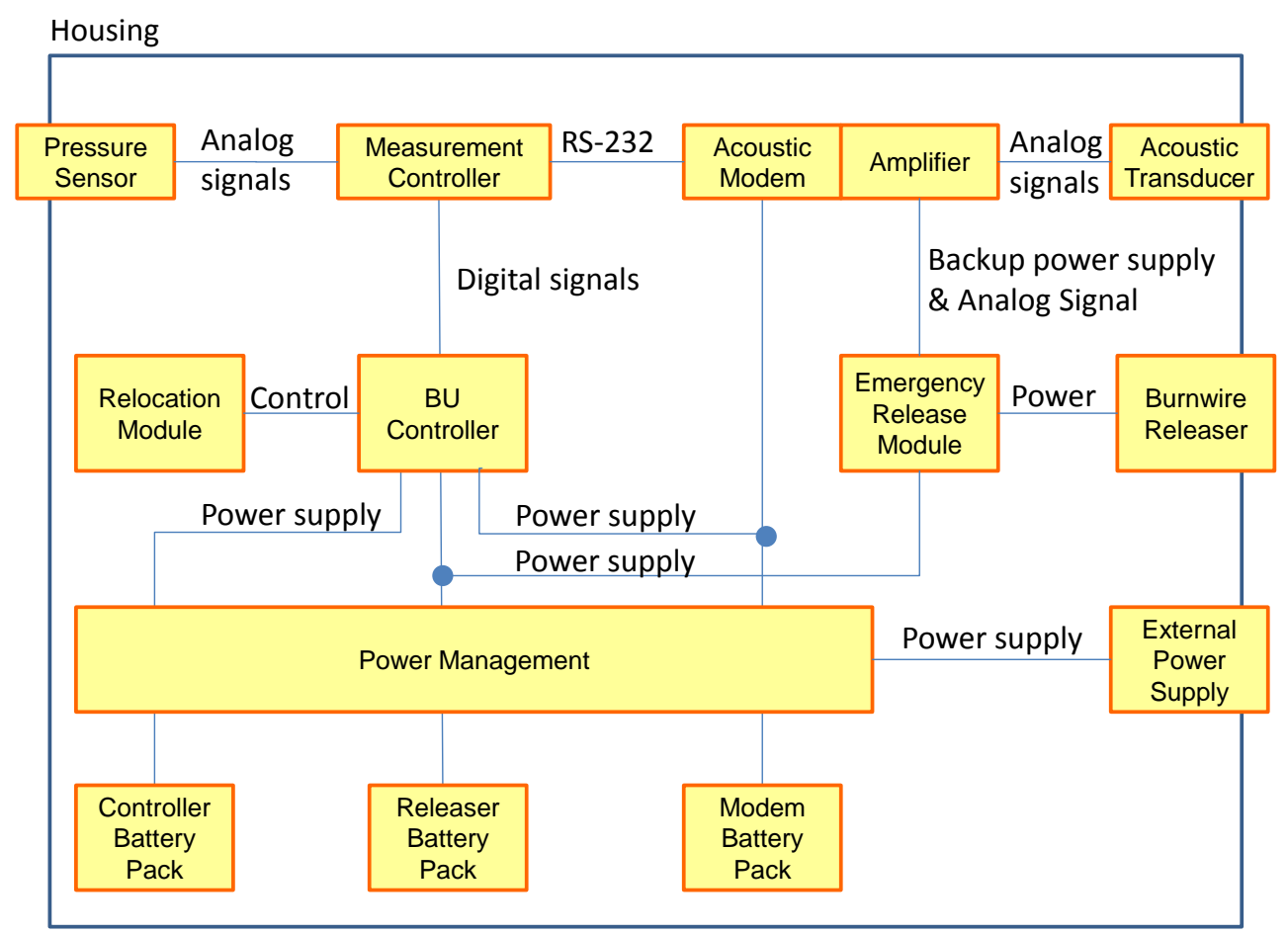

Fig. 11. Schematic diagram of functional groups of the PACT-BU.

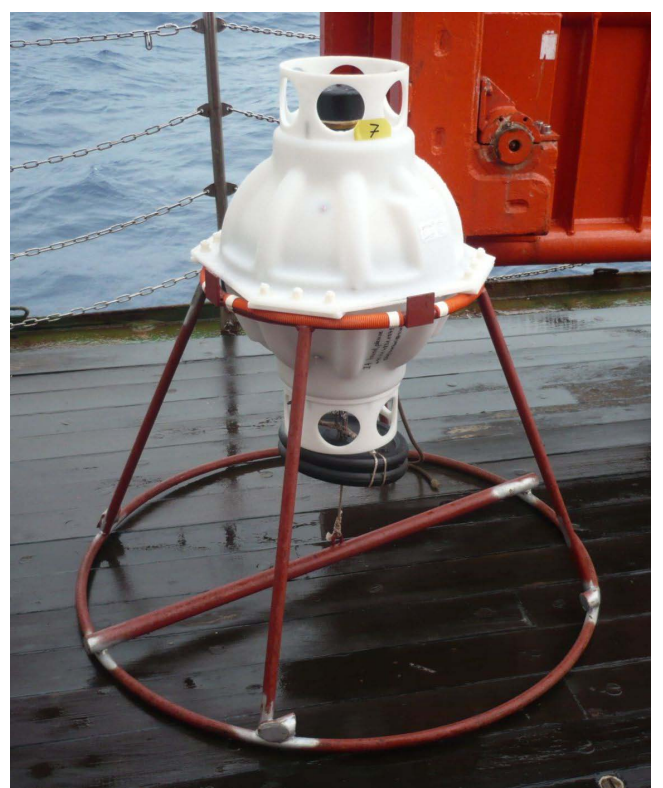

Fig. 12. PACT bottom unit and steel stand. The black cylinder at the top is the modem; the burn-wire release of the BU is located in the lower cage. For deployment, additional weights are attached between the release and the steel stand.

\subsection{System hardware}

The PACT bottom unit (Figs. 11 and 12) is housed by a single $17^{\prime \prime}$ Vitrovex glass sphere with plastic hard hat, containing all components of the instrument (OPTIMARE Sensorsysteme AG, 2008). The instrument is rated for a maximum pressure of $6000 \mathrm{dbar}$. The mechanical layout of the PACT-BU closely resembles the design of the Pressure Inverted Echo Sounder (PIES) developed by the University of Rhode Island (Chaplin and Watts, 1984; Kennelly, 2009; University of Rhode Island, 2006). Glass sphere, pressure sensor, release and steel stand are essentially identical to PIES, which have proven highly reliable in many oceanographic studies throughout the last three decades (Tracey et al., 2009).

The PACT-BU uses a piezo crystal (Paroscientific Digiquartz model $410 \mathrm{~K}$ ) as pressure sensor, which has a resolution equivalent to $1 \mathrm{~mm}$ of sea-level change. The PACTBU averages pressure over a period of $15 \mathrm{~s}$ time (set by a temperature-compensated reference frequency by integrating the number of Digiquartz oscillations during this period). A custom designed, microcontroller-based, on-board computer optimized for low power consumption performs the tasks of pressure measurements, on-board tsunami detection and modem control. For the acoustic transmission of data and alarm messages to the surface unit, the BU is equipped with a HAM.node hydroacoustic modem (develogic $\mathrm{GmbH}, 2008$ ) (cf. Sect. 2). 
A battery package of 86 (ver. 2009) or 91 (ver. 2010) Lithium D-size cells with a total capacity of $4025 \mathrm{Wh}$ (ver. 2009)/4259 Wh (ver. 2010) provides power for the controller, modem and release and is designed for more than two years of operation in normal capturing mode.

The modem of the bottom unit is integrated in the BU housing, and powered by a separate subset of batteries. The projected lifetime of the $2527 \mathrm{Wh}$ (ver. 2009)/2948 Wh (ver. 2010) modem battery pack in the bottom unit allows about 29 months between service, assuming one status message every $4 \mathrm{~h}$, a capturing tsunami event once per week (false alerts or tests), and the need of 1.1 acoustic attempts per successful transmission at a power setting of $80 \%$. However, this estimate also depends on multiple additional factors that are difficult to predict, such as the battery capacity as a function of the actual drain history, the impedance response of the transducer to the actual pressure and of course the actual frequency of "capturing tsunami modes", resulting in an estimated tolerance of $+10 \%$ to $-30 \%$. Additional battery capacity may be made available in future versions by disabling the HAM.node's real time clock, which is powered up but not used in the current setup.

In case that the PACT-SU fails or is running out of power, acknowledgement of the reception of acoustic messages from the PACT-BU cannot be issued by the PACT-SU. Consequently, power consumption of the bottom unit would increase due to repeated transmission attempts, reducing the operational lifetime (but not the emergency release function, see next section) of the PACT-BU.

The PACT-BU is configurable (in the lab or onboard prior to deployment) via a PC based serial terminal connection over wireless network (IEEE802.11b/g) using the PACT-BU commands (Fig. 8).

\subsection{Deployment and recovery}

The BU is deployed in an expendable steel frame while tied with its release hook to an anchor weight (Fig. 12, black weights right below white unit), ensuring a stable position of the system at the seafloor. The entire assembly is designed for a free-fall deployment. The PACT-BU features tilt sensors which allow verifying the upright orientation once the system settled at the sea-floor, a necessity for optimal acoustic communication with the surface unit.

To recover the instrument, an individually coded acoustic signal has to be sent via a transducer deployed from a vessel. PACT provides two options to activate the release mode: firstly, a particular command can be sent via a HAM.node modem directly. Secondly, in case that the modem battery has already been depleted, parts of the acoustic modem are powered by the separate release battery. Although no data messages are then being transmitted, bit-encoded $12 \mathrm{kHz}$ acoustic commands from an Edge Tech Inc. 8011A deck-unit can still be processed by the release module. This emergency release function allows a recovery of the bottom unit even $1-$

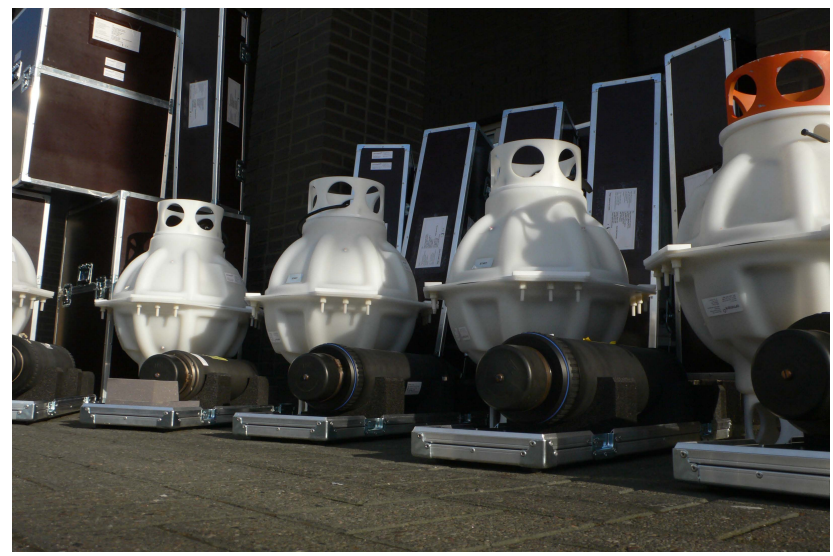

Fig. 13. 5 PACT Bottom Units in "hard hat" protective housing (white) with Ham-Node Modems (olive) ready for shipping to Indonesia. Shipping boxes (brown with aluminium rims) are visible in the background.

2 years (limited by the stand-by current of the acoustic modem) after the normal acoustic operation has ceased.

When the BU detects an acoustic release command, a burn wire release is activated, dropping the anchor weights after 5-20 min. The instrument then rises at about $0.75 \mathrm{~m} \mathrm{~s}^{-1}$ to the surface; due to the BU's internal weight distribution, it will turn upside down, with the acoustic modem pointing downward into the water, a configuration that has successfully been used in PIES to range instruments even when at the sea-surface (D. R. Watts, personal communication). At the surface, a relocation module including a bright xenon strobe and a VHF transmitter aids the recovery of the instrument. Starting with PACT-BU ver. 2009, the relocation module is also activated whenever the BU turns upside down, i.e. after an accidental loss of the anchor weights without a prior release command.

\subsection{First results}

\subsubsection{Overview}

During the three years of PACT's development, numerous field and laboratory tests were performed to evaluate the stability of data acquisition, processing and acoustic communication sub-systems. Extended laboratory tests included highpressure loading, simulating tsunami-like pressure anomalies, remote acoustic control of the bottom unit, a simulation of the surface unit to buoy interaction and an end-to-end test from the PACT-BU to the host buoy's computer. A first at-sea test under realistic conditions was performed at the DOLAN (Datenübertragung im Ozean und Laterales Akustisches Netzwerk in der Tiefsee) mooring site (MARUM, 2010) located $60 \mathrm{~nm}$ north of the Canary Islands. In November 2007, a PACT bottom unit was deployed at a depth of $3300 \mathrm{~m}$ in the 
vicinity of the DOLAN mooring, while a HAM.node modem was attached to the DOLAN surface buoy.

Via an Iridium satellite link, direct communication could be established between the lab and the surface and bottom units. For the period 6 November 2007 through 14 April 2008 (i.e. 151 days) the bottom modem was contacted twice daily for 301 times, with 268 pings successful and 33 pings terminated due to timeouts. This, however, was most likely caused by a timeout of the Iridium modem rather than a failure of the underwater modem communication. Hence, this result implies successful underwater communication in at least $89 \%$ across a distance of $3900 \mathrm{~m}$ and even under adverse weather conditions with wind speeds up to $15 \mathrm{~m} \mathrm{~s}^{-1}$ (NCEP reanalyses; Kalnay et al., 1996) and significant wave heights up to $4 \mathrm{~m}$ (calculated from AVISO altimetry products).

For the first embedded deployment of PACT as integral component of the GITEWS hardware in Indonesia, five (plus one spare) PACT systems (Fig. 13) were prepared and shipped for deployment during RV Sonne expedition SOTEWS-1/2 to occupy five (including the deepest) deep ocean mooring locations (Sumatra 2, 1, 3 and 4 as well as Java 1 in order of deployment, cf. Fig. 3). During this cruise, PACTdaemons were installed on each host buoy's computer while PACT-SUs were mechanically attached to the mooring line and electrically connected via underwater cable to the surface buoy by the buoy operators. After each deployment of the surface buoy, all PACT-SUs were tested remotely via Iridium link and confirmed operational. Then, PACT-BUs were launched in close vicinity of the surface mooring while monitoring their descent to the sea floor with a second surface modem which was lowered to the side of the ship.

While the overall success of this first deployment was limited, it was nevertheless demonstrated that the communication concept stably operates end-to-end, as pressure data from 2 systems deployed at the deepest locations (Sumatra 3 and Sumatra 4) were reliably recorded, transmitted and received ashore for several weeks, while system commands issued ashore were processed as expected by the BUs at the sea-floor.

Throughout the deployment period off Indonesia, wave heights (calculated from AVISO altimetry products) averaged around $1.70 \pm 0.25 \mathrm{~m}$ at both positions, while wind speed (calculated from NCEP 4-times daily reanalysis values; Kalnay et al., 1996) was $3.2 \pm 1.8 \mathrm{~m} \mathrm{~s}^{-1}$. Both wave heights and wind speeds are lower than during the monsoon season in July-September $\left(2.3 \pm 0.4 \mathrm{~m}\right.$, and $7.4 \pm 2.6 \mathrm{~m} \mathrm{~s}^{-1}$, respectively). Rainfall (relevant for acoustic noise), in contrast, was representative for the annual distribution. Nevertheless, acoustic transmission functioned even at times of rainy and windy $\left(9 \mathrm{~m} \mathrm{~s}^{-1}\right)$ days with wave heights of $2.1 \mathrm{~m}$, (based on NCEP and AVISO records, not shown), and also during occasionally more severe conditions of the 6-months test deployment at DOLAN.

The data flow from BU \#2 ceased after 14 days due to malfunctioning of hardware components external to PACT, i.e.

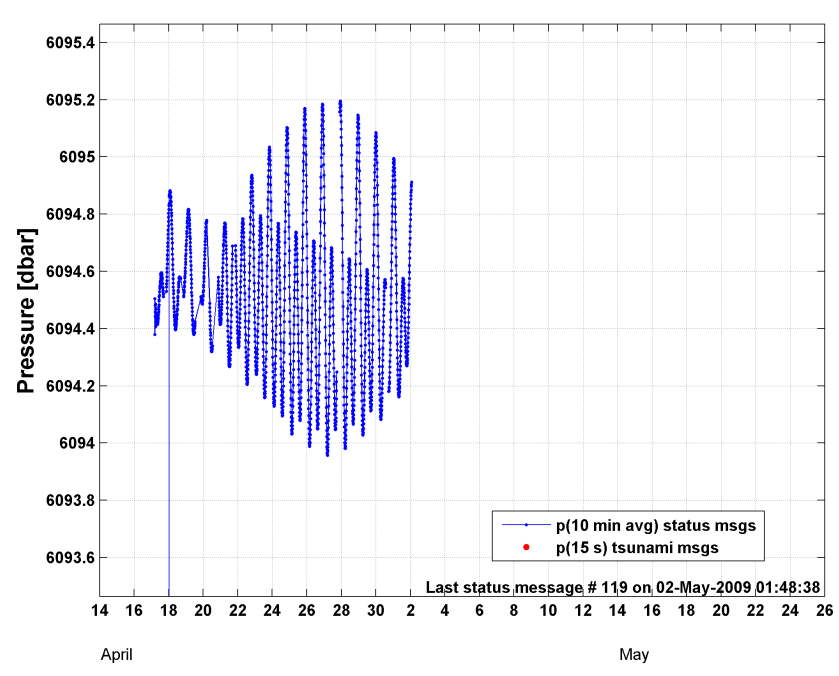

Fig. 14. Summary of 14 days of real time data from position Sumatra 4. Blue dots represent 10-min pressure averages (transmitted via status messages). Limits of time axis as for figure depicting pressure data at Sumatra 3 (Fig. 15).

due to a loss of contact between the communication satellite and the surface buoy at Sumatra 4. The communication between the PACT-SU and surface buoy at Sumatra 3 became increasingly impaired due to a break in the buoy's underwater communication cable, before finally ceasing after 37 days of operation (Table 2). Indeed, during a buoy maintenance cruise in November 2009, damaged wire leads were found in the umbilical cord connecting the PACT-SU with its hosting buoy.

Regrettably, of the 5 PACT systems deployed during the cruise, 3 PACT-BUs (\#4 at Sumatra 2, \#6 at Sumatra 1 and \#1 at Java 1, cf. Table 2) failed shortly after launch, with PACT BU \#4 being found adrift by a fisherman a few weeks later and returned to Germany for analysis. The problems that had led to these premature failures of the PACTBU (ver. $2009^{3}$ ) during the deployment phase have meanwhile been identified and corresponding design modifications (ver. 2010) are expected to prevent future failures of similar kind. Three new PACT-BU systems have been prepared to be deployed at the next possible opportunity.

\subsubsection{Data acquisition and automatic tsunami detection}

After transition from deployment mode to capturing normal mode, the PACT-BU at locations Sumatra 3 and 4 regularly delivered records of 10-min bottom pressure data for several weeks (time series shown in Figs. 14 and 15). The data clearly show the semidiurnal tides (of up to $1 \mathrm{~m}$ amplitude) with diurnal and fortnightly modulations in the 10-min

\footnotetext{
${ }^{3}$ The indicators "ver. 2009" and "ver. 2010" refer to the respective production dates of the PACT-BU.
} 


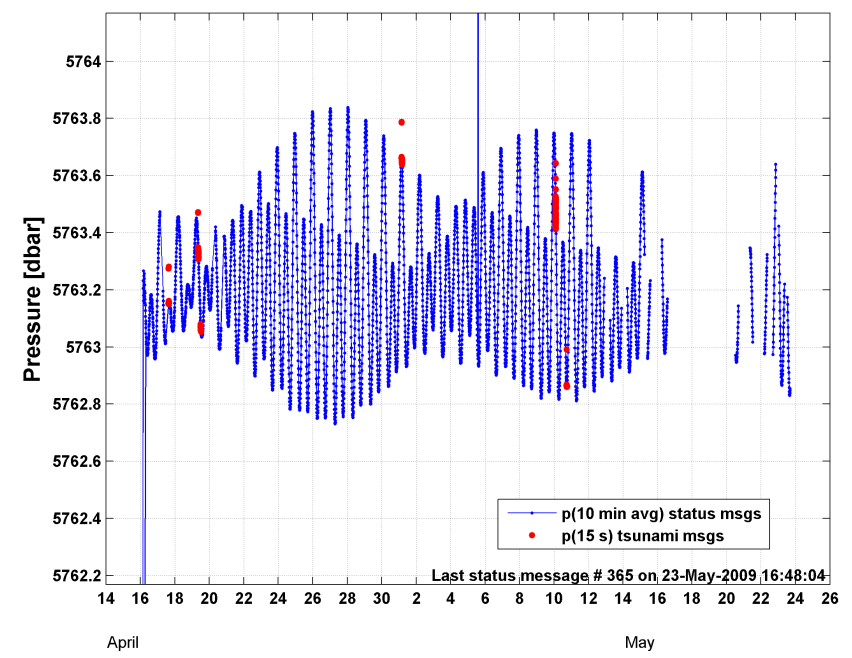

Fig. 15. Summary of approximately 37 days of real time data from position Sumatra-3. Blue dots represent 10-min pressure averages (transmitted via status messages), red dots 15-s instant data (transmitted as part of tsunami messages when system was in capturing tsunami mode).

averaged pressure records (outliers are caused by spikes, as discussed below).

At Sumatra 4 (BU \#2, Fig. 14), 57 of 59 status messages (97\%) were received after 22 April 2009, once the surface modem's detection thresholds had been optimized. Thereafter, only two messages were lost, and apparently no repeat transmission attempts were started by the BU (evident in stable modem battery voltage after 22 April 2009, Fig. 18) despite of this station being the deepest of the entire GITEWS array. No false tsunami alarms were triggered; also the system status (Fig. 18) shows stable conditions. On 2 May 2009, all satellite communication with the surface buoy ceased, hence no PACT data were received thereafter.

At Sumatra 3 (Figs. 15 and 19), transmission success rates were 98\% from 22 April 2009 (after initial adjustment of the surface modem) until 12 May 2009, when a loose contact in the cable connecting surface modem and buoy caused transient interruptions of increasing duration in the communication between the hosting surface buoy and the PACT-SU, until a last message was received on 23 May 2009. During this period, 121 of 122 status- and 30 of 32 tsunami-messages (as generated by 2 tsunami events) were received resulting in a total of 151 messages.

Unlike BU \#2, this BU triggered several tsunami alarms (Fig. 15) due to what appear to be double- and triple-spikes in the pressure record. The system parameters (Fig. 19) of this BU are nevertheless stable. During tsunami alarms, which result in increased modem activity, the internal temperature increases by a few tenths of a degree, an effect that was already noted during bench-tests. As temperature measurements by the internal SHT sensor are collected at a rate of
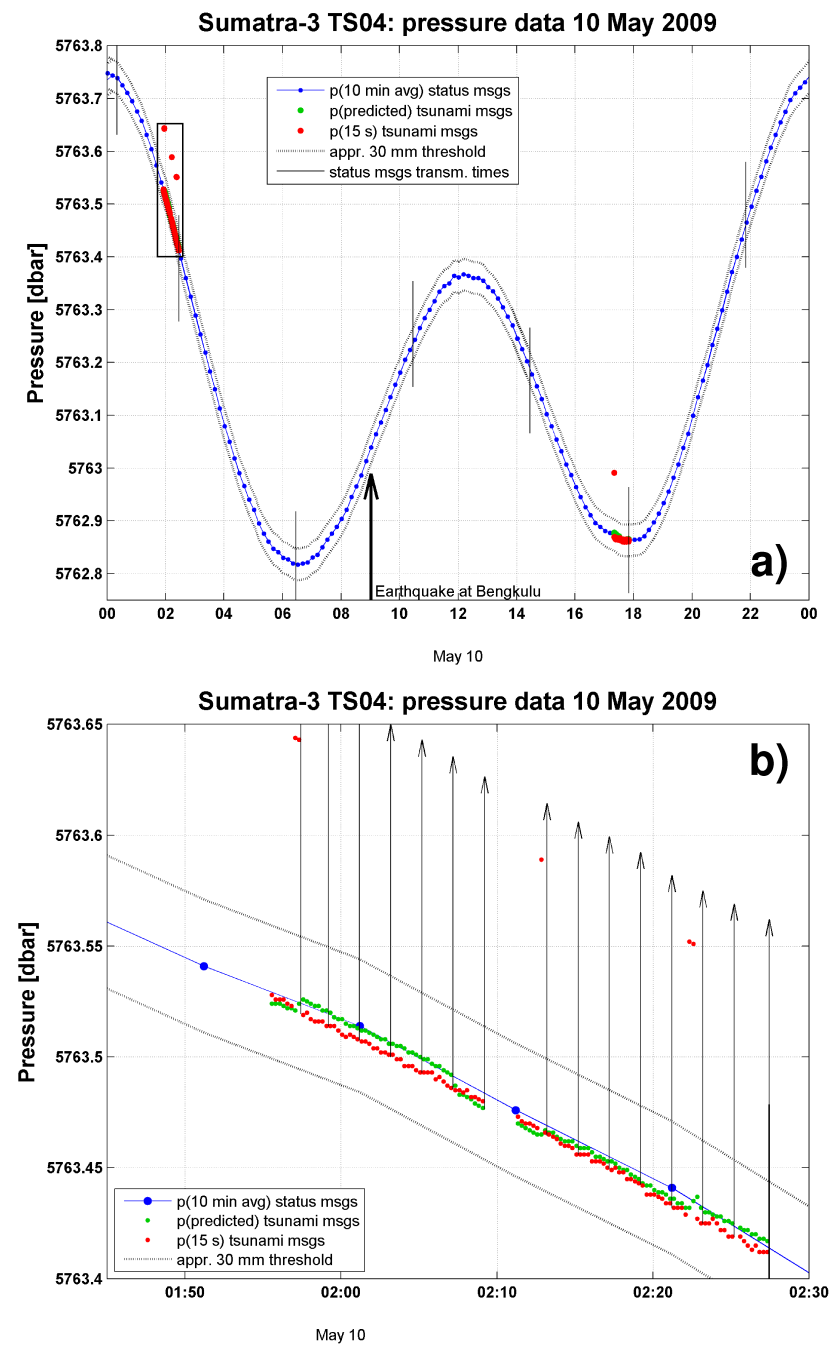

Fig. 16. (a) Bottom pressure data from position Sumatra-3 on 10 May 2009. Red dots indicate in-situ pressure data during two false tsunami alarms (triggered by spikes in the pressure record). The time of Bengkulu earthquake is marked by a bold arrow. Vertical lines indicate the timing of status message transmissions. (b) Zoomin of the first (false) tsunami alarm. Arrows indicate the timing of alarm messages. Note the 2 consecutive false measurements at about 01:58, triggering the transmission of the first alarm message immediately after. Later outliers do not re-trigger the tsunami mode. At 02:10, a single alarm message (containing 8 data points from the last $2 \mathrm{~min}$ ) is missing. The first tsunami message contains 6 normal values followed by the first two outliers. The predicted pressure values (green dots), however, increase by $5 \mathrm{~mm}$ after the 7 th data point, when the last $10 \mathrm{~min}$ average polynomial node starts to be affected by the outlier.

once per hour only, the warming of the BU during the capturing tsunami mode results in false estimates of the bottom pressure. However this error is negligible when monitoring for tsunamis, as it only amounts to less than $10 \mathrm{~mm}$ for the temperature increases observed. 


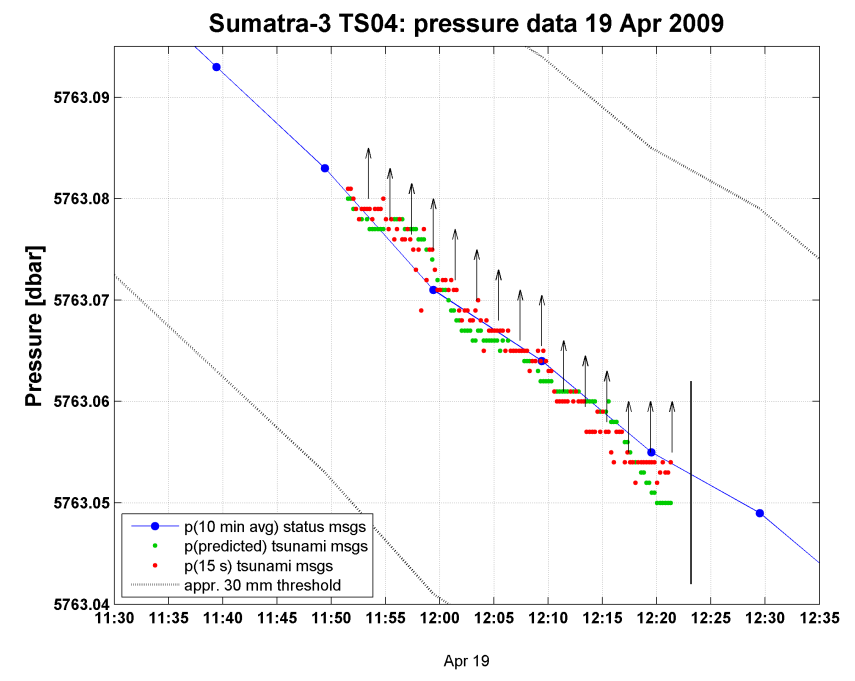

Fig. 17. Bottom pressure data during an externally triggered tsunami alarm on 19 April 2009 from position Sumatra 3. Blue dots: 10-min averages. Red dots: measured 15-s data; Green dots: predicted data (based on cubic polynomial over past $3 \mathrm{~h}$ ). Dotted lines indicate $30 \mathrm{~mm}$ tsunami threshold which is far outside the noise of the measurements during normal conditions. Vertical arrows show timing of alarm messages, vertical line of consecutive status message after the alarm timed out.

Nevertheless, this BU (\#8) is suspected to have some sensor or electronics faults, as indicated by several false tsunami alarms (Fig. 16, red dots near 02:00 $\mathrm{h}$ and 17:00 h) and occasional sign errors of tilt " $X$ " (Fig. 19). The false alarms occurred due to false pressure measurements (example shown in Fig. 16) with always three consecutive data points being $0.12 \mathrm{dbar}$ higher than the predicted pressure, thus passing the spike criterion and triggering a tsunami alarm after the second outlier. Capacitive coupling to ground between the pressure sensor and acoustic modems which could result in the spikes as suggested by one reviewer can be excluded as possible cause, due to a clear temporal mismatch between acoustic transmission and spikes (Fig. 16). Rather, recent lab testing of an identical system revealed that such spikes were caused by a resistor of false value in the data acquisition module. The Bengkulu earthquake on 10 May 2009 of magnitude Ms 5.1 (USGS (United States Geological Survey), 2009) did not trigger any tsunami alarm (Fig. 16a, black arrow).

A capturing tsunami mode was actively triggered by remote command on 19 April 2009, testing the option of setting the BU into this mode prior to any possible tsunami event (Fig. 17). The pressure readings show a noise level close to the numerical resolution of the system $(0.001 \mathrm{dbar}$, equivalent to $1 \mathrm{~mm}$ water column height) and pressure anomalies $h_{k}-H_{f}$ less than $3 \mathrm{~mm}$. An oscillation at a timescale of 10 min might suggest the presence of some long waves or aliasing of some interference of different short surface waves

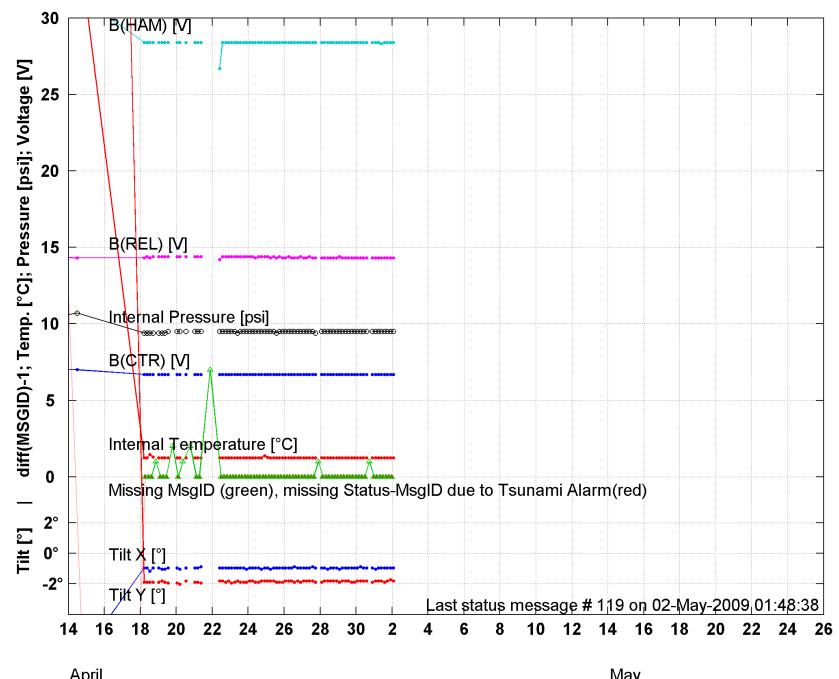

Fig. 18. Status information from BU 002 at location Sumatra 4. Legend as follows unless self explaining: $\mathrm{B}(\mathrm{HAM})$, cyan $=$ modem voltage in $\mathrm{V} ; \mathrm{B}(\mathrm{REL})$, magenta = emergency release voltage; $\mathrm{B}(\mathrm{CTR})$, blue = BU-controller voltage; Tilt $\mathrm{X}$ and $\mathrm{Y}($ blue, red $)=$ tilt of bottom unit relative to vertical; Missing Msg ID (green) = number of missing messages since last transmission due to communication failures (" 0 " indicates zero lost messages, " 1 " i.e. a single lost message, etc.). No tsunami alarm occurred at this unit.

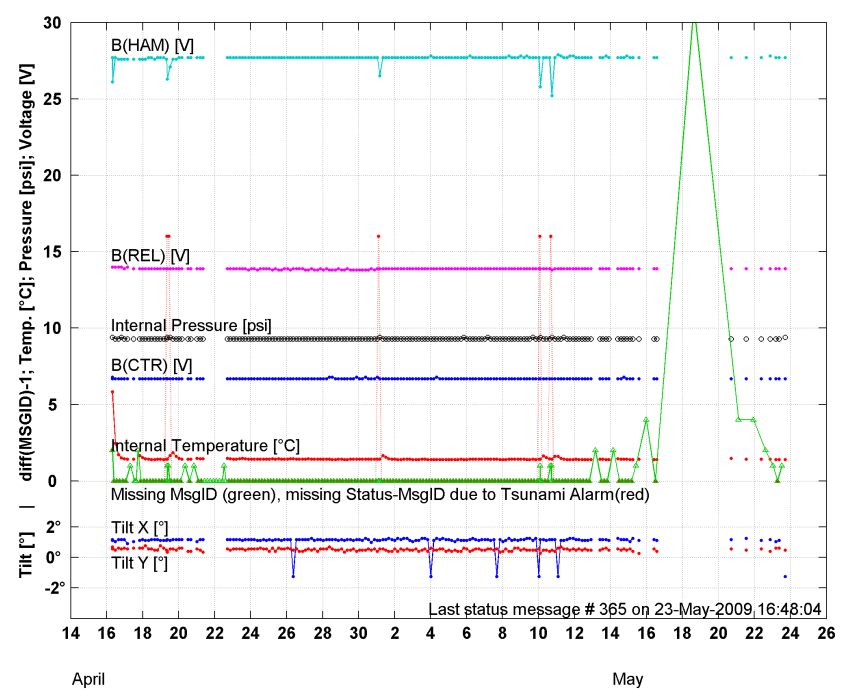

Fig. 19. Status information from BU 008 at location Sumatra 3. Legend as in Fig. 18. Red peaks at "16": Tsunami alarm with (nominally) 16 tsunami messages.

(Gennerich and Villinger, 2009). Nevertheless, the tsunami alarm threshold of $30 \mathrm{~mm}$ is far beyond these observed pressure fluctuations. 


\subsubsection{Energetic performance}

As described above, the PACT-BU comprises three separate battery packs for the modem, the BU-controller board and the release system. Battery records are contained in the status messages and were retrieved for BU \#2 (Fig. 18) and \#8 (Fig. 19) at Sumatra 4 and 3, respectively. For both systems, the nominal battery voltage was maintained for the duration of the data record lengths of 38 days and 14 days. The only exception occurred during capturing tsunami mode, when the increased amount of acoustic transmissions lead to a voltage drop of about $2 \mathrm{~V}$ in the modem battery (Fig. 19, B(HAM)).

The fortunate retrieval of $\mathrm{BU} \# 4$ also allowed checking the battery packs more than 9 months after deployment (on 26 January 2010). The modem battery was completely depleted ( $V_{\mathrm{HAM}}=0 \mathrm{~V}$; versus $32.4 \mathrm{~V}$ at deployment) due to an internal short out. By contrast, the voltage of the PACT CPU battery $\left(V_{\mathrm{CTR}}=7.0 \mathrm{~V}\right)$ was still close to its deployment value of $7.2 \mathrm{~V}$, much like the emergency release battery $\left(V_{\mathrm{REL}}=14.3 \mathrm{~V}\right.$, versus $14.4 \mathrm{~V}$ at deployment).

The possibility of a short-out in the modem's power supply had already been noted during the deployment cruise. After a test of BU\#8, the unit's modem power regulator was found short-circuited. Subsequent onboard and parallel laboratory tests revealed that transient voltage peaks (e.g. during high loads or connect/disconnect operations) could possibly cause short-circuiting in the modems voltage regulator. This problem had slipped previous lab-tests, because, while inair, the modems were operated at reduced power to avoid damaging the transducer and on an external power supply of higher internal resistance to retain the batteries' full capacity. Noting that none of the PACT-SUs, which are equipped with rechargeable batteries of nominal $25.2 \mathrm{~V}$ had shown similar problems, the BU's modem battery appeared as the critical component.

To eliminate any chance occurrence of this problem, beginning with BU \#8 at Sumatra 3, peak power settings were reduced from $97 \%$ to $90 \%$ and modem battery packs were reconfigured at sea from $32.4 \mathrm{~V}$ to $28.8 \mathrm{~V}$ (nominal). This resulted in a reduction of battery capacity by $11 \%$. Apparently, this seems to have solved the problem, and BU\#8 and \#2 performed well in this regard, while the failure of BU\#7 is attributed solely to the lost drop weight, as its acoustic power level had been reduced to $60 \%$ due to its shallowness.

A post-cruise battery re-layout implemented now in PACT-BU v2010 operates at a modem operating voltage of $25.2 \mathrm{~V}$ (nominal) from 9 parallel battery packs (compared to 6 originally) while shifting capacities from the controller batteries $(-25 \%)$ to the modem battery $(+17 \%$, each with regard to the original design).

\subsubsection{Deployment and recovery}

The system deployment involves three steps: The installation of the SU at the surface buoy, the mooring of the sur- face buoy ${ }^{4}$, and finally the launch of the PACT-BU. At three locations (Sumatra 2, Sumatra 1, and Java 1, in order of deployment) the surface buoy moorings were deployed immediately prior to the launching of the PACT-BU (Table 3). The surface buoy mooring was deployed "anchor last", i.e. the surface buoy mooring assembly was spread linearly on the sea surface with the anchor weight being attached as the last element. Upon release of the anchor weight, the anchor drops while dragging the mooring assembly down with it. PACTBUs were dropped within a few minutes of the release of the anchor weight, and hence sank to the bottom concurrent to the righting process of the surface buoy mooring.

By contrast, at the other two locations (Sumatra 3 and 4) surface buoys had already been moored during a previous cruise and did not require redeployment during this cruise. In these cases, PACT-BUs were dropped at a nominal distance of $200 \mathrm{~m}$ from the buoy and hence represented the only moving object in the water column while falling. It is worth noting, that these 2 systems touched down well and started their mission as planned. By contrast, the three PACT-BUs that were dropped concurrently with the righting of the surface mooring system, failed. While we do not think this to be the reason for the failure of these 3 systems, this concordance nevertheless suggests dropping the PACT-BU preferably only once the surface buoy mooring is fully upright. In fact, this procedure would also help minimizing spatial errors resulting from buoy set-back when deploying the PACT-BU prematurely.

PACT-BU drop speeds of $1.8 \mathrm{~m} \mathrm{~s}^{-1}$ and $1.6 \mathrm{~m} \mathrm{~s}^{-1}$ were calculated from the full pressure record as retrieved from the internal log-file of BU\#4 at Sumatra-2 (system weight $96 \mathrm{~kg}$ ) and from 3 intervals of 4 deployment messages during the free fall phase of BU\#2 at Sumatra 4 (system weight $66 \mathrm{~kg}$ ). Both values showed a high stability between individual data records. A drop speed of greater $1.4 \mathrm{~m} \mathrm{~s}^{-1}$ was estimated from the period between launch and the first received message from the sea-floor of BU\#8 at Sumatra 3. However, prior to transmission of this message, the instrument probably had been resting at sea-floor for an unknown period, rendering this value a lower bound estimate only.

With the mechanical dimensions of PACT being similar to the PIES design, like behaviour regarding the free-fall deployment and recovery of PACT were expected. However, the abovementioned speeds are up to $50 \%$ higher than speeds known for PIES (Böning et al., 2010). These increased speeds may likely have lead to the premature failure of BU\#4 at Sumatra 2 and BU\#7 at Java 1. At touchdown, higher sinking speeds induce increased strain on the release block, which possibly leads to a failure of the release

\footnotetext{
${ }^{4}$ The entire complex of the surface buoy (system design, deployment and maintenance) is organized under GITEWS work package "GPS surface buoy" (Deutsches GeoForschungsZentrum, GFZ). With regard to PACT, the buoy merely acts as a host providing communication and power to and from the PACT surface unit.
} 
Table 3. Mooring locations, associated equipment and deployment methods.

\begin{tabular}{lccll}
\hline Location & Host buoy & BU S/N & Depl. strategy host buoy & Depl. Strategy PACT-BU \\
\hline Sumatra 2 & TS07 & $\# 4$ & anchor last & Concurrent (+1 min) \\
Sumatra 1 & TS06 & $\# 6$ & anchor last & Concurrent (+12 min) \\
Sumatra 3 & TS04 & $\# 8$ & NA (already deployed) & Post (200 m distance) \\
Sumatra 4 & TS09 & $\# 2$ & NA (already deployed) & Post (200 m distance) \\
Java 1 & TS 10 & $\# 7$ & anchor last & Concurrent (+few min) \\
\hline
\end{tabular}

wire/pin assembly, causing an early and unnoticed release of the bottom unit. The mechanical failure of the release pin in fact was confirmed upon inspection of PACT-BU\#4 after its incidental recovery. The release block lacked the release pin, but the burn wire was still in place and bent open, allowing the pin to have slipped out of its hold and releasing the BU's anchor weight. The pressure records stored in the $\log$ file of BU\#4 at Sumatra-2 reveals that this instrument touched the sea-floor only briefly before starting to ascend, suggesting that the drop weight was lost upon impact. From PACT-BU\#8 at Java 1, only a single message was received $12 \mathrm{~min}$ after launch, indicating a depth of about $14 \mathrm{~m}$. At the sink speeds calculated above, however, the instrument would be expected at about $1150 \mathrm{~m}$ depth at this time, which also indicates an early release of the PACT-BU from its anchor.

Strain tests in the laboratory meanwhile revealed that the original release pin assembly did indeed break at a strain of 0.9 to $1.6 \mathrm{kN}$, which is significantly below the specifications of $3 \mathrm{kN}$. Modifications to the pin assembly's material and design now result in specimens with tested breaking strain limits $>3 \mathrm{kN}$. System weight will be further reduced in future deployments, rendering similar problems unlikely.

Last but not least, the ascending speed of BU\#4 was $0.75 \mathrm{~m} \mathrm{~s}^{-1}$, a value consistent with observations made during the recovery of PIES (Böning et al., 2010).

\section{OBU $^{5}$}

\subsection{Rationale}

It is well known that tsunamogenic earthquakes nucleate at the plate boundary between the downgoing and the overriding plates. The seismogenic zone is generally located offshore, and thus the hypocenter is poorly located when only a land based array of seismometers is available for a rapid determination of the earthquake location. Errors of up to $30 \mathrm{~km}$ have been reported from other subduction zones (Hasegawa et al., 1994; Husen et al., 1999). Therefore, augmenting the land based arrays by a few marine stations, located seawards of the seismogenic zone, will make rapid hypocenter deter-

\footnotetext{
${ }^{5}$ The OBU was developed under the auspices of IFM-GEOMAR in collaboration with develogic $\mathrm{GmbH}$.
}

mination more reliable. This was the main motivation to develop an OBU, which in addition to a pressure sensor also carries a broadband seismometer and hydrophone.

Furthermore, pressure changes at the seafloor with amplitudes and frequencies of typical tsunami signals can also be caused by events other than tsunamis. Besides rare events caused by mechanical contact with sea-floor fauna and possibly meteorological signals, the main source for pressure changes at the seafloor are surface waves from large teleseismic events. It is straight forward to discriminate between a tsunami signal and a teleseismic surface wave once pressure and seismometer data are available. Therefore, such a combined data set will help to reduce the number of false alarms.

\subsection{Data flow, command, and control}

Like PACT, the OBU is a free fall lander system, to be deployed close to a surface buoy to enable acoustic data transmission from the OBU to the sea surface and further to the EWMC. Both the seismic and the pressure data are continuously stored onboard the OBU, with a storage capacity for at least 12 months. The pressure data are transmitted at preset time intervals. When a tsunami signal is detected, an alarm is issued - similar to the PACT system. The seismic data are stored in the $\mathrm{OBU}$, and are transmitted upon request from the EWMC. The seismic data stream to be transferred to the EWMC has to be specified with a start and end time. The data transfer will be at a rate allowing a data transmission close to real time.

During service intervals (once per year), all data can be downloaded and saved in international data repositories. In addition, the internal time base of the OBU may be adjusted to UTC. The typical drift of the internal Seascan clock is about $1 \mathrm{~ms}$ per day, with drifts being almost linear, permitting a post-retrieval correction. Real-time clock corrections may be implemented at the EWMC with a high degree of confidence on the basis of accurate pre-deployment drift measurements.

\subsection{System hardware}

The OBU closely follows the design of the IFM-GEOMAR Ocean Bottom Seismometer (OBS), that have been in use for many years (Bialas and Flueh, 1999), augmented by an 


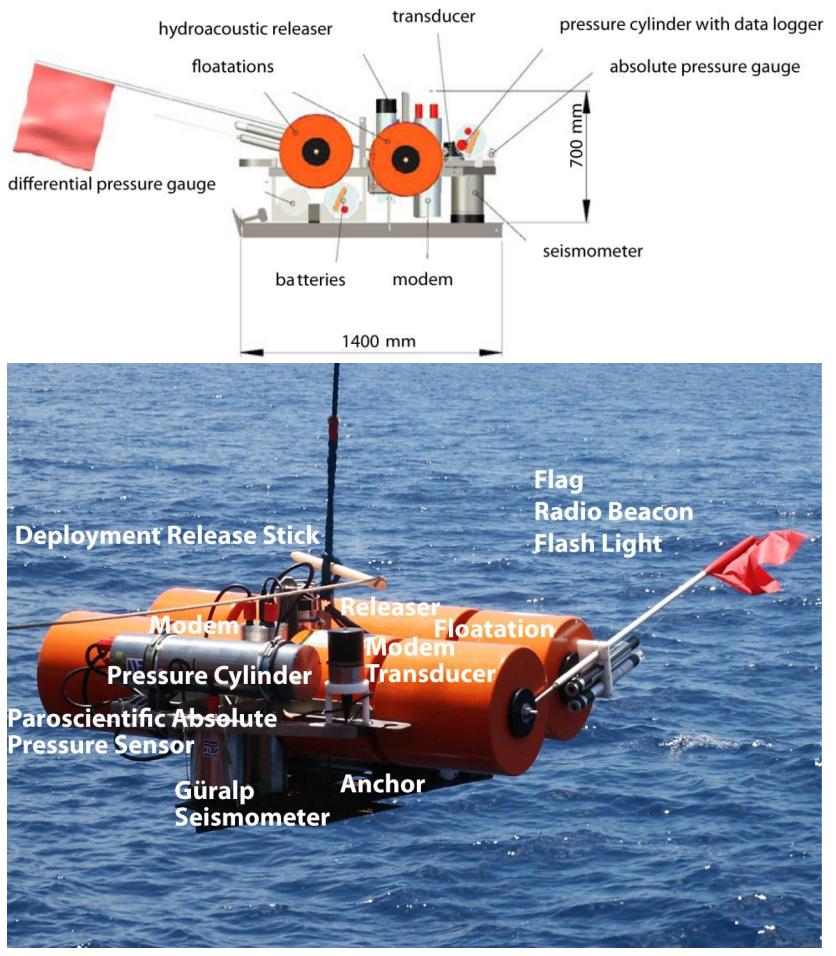

Fig. 20. Sketch and photo showing the OBU just before deployment.

acoustic modem which also serves as system controller. The OBU (Fig. 20) consists of a custom-built titanium instrument carrier designed to assemble the components described below. Titanium was chosen for all components to guarantee minimal corrosion problems. For buoyancy, eight cylindrical floatation bodies made from syntactic foam are used. This syntactic foam is rated for $6000 \mathrm{~m}$ of water depth, as are all other components. The in-air weight of the anchor $(50 \mathrm{~kg})$ is such, that the weight in water is $20 \mathrm{~kg}$ for descent. After releasing the anchor, the OBU's buoyancy is $30 \mathrm{~kg}$. This results in a speed through water of $1 \mathrm{~m} \mathrm{~s}^{-1}$ for descent and ascent. The weight of the instrument in air is $200 \mathrm{~kg}$.

The acoustic release is an IXSEA/Oceano Release RT661, also inside a titanium cylinder. It is mounted in the central position of the OBU. Upon reaching the surface, the OBU will tilt by $90^{\circ}$ and thus ensures that the releaser transducer is still under water to enable ranging between the service vessel and the instrument. As additional relocation aids, a radio beacon, a flash light and a flag are attached to the OBU, see Fig. 20.

Data telemetry, bottom pressure data acquisition and tsunami detection functionality are provided by a HAM.node modem (see Sect. 2) with an integrated 8CB7000-I Paroscientific absolute pressure sensor. Pressure data are acquired and stored every $15 \mathrm{~s}$. The DART ${ }^{\circledR}$ tsunami detection algorithm is used for event detection. Seismic data can be requested from the seismic recorder upon demand from the EWMC.
Both bottom and surface modems as used for the seismic OBU are equipped with directional transducers operating in the frequency range from $11.2 \mathrm{kHz}$ to $\sim 19.2 \mathrm{kHz}$. In order to achieve the higher data throughput necessary for transmission of seismic data, an m-DPSK modulation scheme is used (see Sect. 2).

The modem is mounted next to the acoustic release and is connected by cables to an external battery pack in a titanium pipe ( $80 \mathrm{~cm}$ long, $15 \mathrm{~cm}$ diameter) and to the SEND seismocorder GEOLON-MTS-M housed in another titanium pipe (62 cm long, $15 \mathrm{~cm}$ diameter). The battery capacity for the modem $(9000 \mathrm{Wh})$ and for the data logger $(3500 \mathrm{Wh})$ ensure a lifetime of about 12 months, although the power requirements for the modem highly depend on the amount of seismic data to be transferred. Modem source levels amount to approximately 205,204 , and $200 \mathrm{~dB}_{\mathrm{rms}}$ re. $1 \mu \mathrm{Pa}$ for power settings of $97 \%, 90 \%$ and $60 \%$, respectively.

The seismocorder GEOLON-MTS-M has been developed by SEND $\mathrm{GmbH}$ and provides long-term acquisition and storage of seismological data. Power consumption is highly optimized (less than $150 \mathrm{~mW}$ ), and the time stability (about $1 \mathrm{~ms} / \mathrm{d}$ ) is provided by a Seascan clock. Data storage is on up to 12 PCMCIA microdiscs or flashcards, each with a maximum capacity of $2 \mathrm{~GB}$. After low pass filtering, the signals from the four seismic channels (three-component seismometer and hydrophone) are digitized using Sigma-Delta A/D converters. A final decimation sharp digital low-pass filter is realized in software by the signal processor. The sample rate can be chosen between 1 and 200 samples per second (sps), and the resolution is between 14 bits at 200 sps and 21 bits at $5 \mathrm{sps}$. The data are further compressed before stored on the PCMCIA devices. The recorder can be parameterized using an ASCII terminal via RS232 interface, and the oscillator is synchronized using GPS pulses. After deployment, parameters can be changed from the warning centre through the satellite/acoustic link.

The seismic sensors consist of a deep-sea differential pressure gauge V66.3 of the Marine EM Laboratory of Scripps Institution of Oceanography (Cox et al., 1984). This sensor has a frequency band from $20 \mathrm{~Hz}$ to $150 \mathrm{~s}$. The seismometer is the CMGOBS40T of Güralp Systems Limited and is mounted in a $17 \mathrm{~cm}$ long titanium pipe $(15 \mathrm{~cm}$ diameter). This sensor is fixed between the instrument carrier and the anchor. It requires levelling once landed on the seafloor, and this is initiated at a preset time through the data recorder. Levelling can be repeated at pre-set intervals (typically 14 days) to adjust for changes occurring on the instrument carrier. This seismometer operates in the frequency range from $20 \mathrm{~Hz}$ to $40 \mathrm{~s}$.

Absolute pressure data from the Paroscientific sensor are polled every $15 \mathrm{~s}$ and fed into the tsunami trigger algorithm. Every $6 \mathrm{~h}$, averaged data ( 2 min intervals) are transferred acoustically via the surface buoy and subsequent satellite connection to the warning centre. The sensor can either 


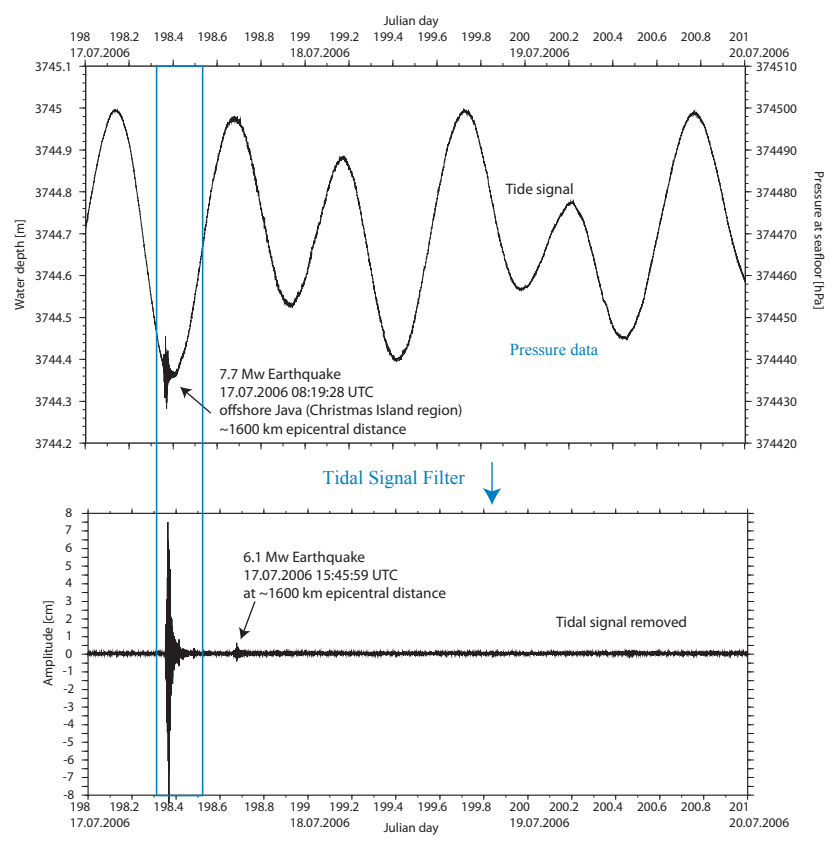

Fig. 21. Example of pressure data recorded by OBU-01b located at $0^{\circ} 25.515^{\prime} \mathrm{S} / 96^{\circ} 51.658^{\prime} \mathrm{E}$ near location GITEWS 1 . Top: raw pressure data; bottom: data after high pass filtering.

be connected to the GEOLON-MTS-M recorder, or alternatively to the HAM.node modem.

\subsection{First results}

Two OBSs recorders were deployed in 2006 during the first GITEWS deployment cruise near the locations of GITEWS surface moorings GITEWS 1 and GITEWS 2 (see Fig. 3). While these systems did not include an acoustic link between the bottom sensor package and the surface buoy, they internally recorded seismic and pressure data for several months. In particular, OBU 01b was deployed on 15 January 2006 during R/V Sonne cruise 186 (GITEWS). The seismic recorder was maintained on 6 March 2006 during R/V Sonne cruise 186 (SEACAUSE), and recovered in November 2006 with the Indonesian R/V Baruna Jaya. A segment of these data, concurrent with two earthquakes of $\mathrm{Mw} 7.7$ and 6.1 which occurred on 17 July 2006 offshore Java at about $1500 \mathrm{~km}$ distance is shown in Figs. 21 and 22. The $\mathrm{Mw}=7.7$ earthquake happened at about $1600 \mathrm{~km}$ epicentral distance. The resulting seismic ground motion induced fluctuations of the (due to $15 \mathrm{~s}$ integration time smoothed) pressure record of $8 \mathrm{mbar}$, which is equivalent to a $\pm 8 \mathrm{~cm}$ sea level change.

\section{Conclusion and overall outlook}

In summary, as based on 4 months of transmitted data, highest reliability of the acoustic underwater transmissions by the HAM.node modem is indicated by both results from the

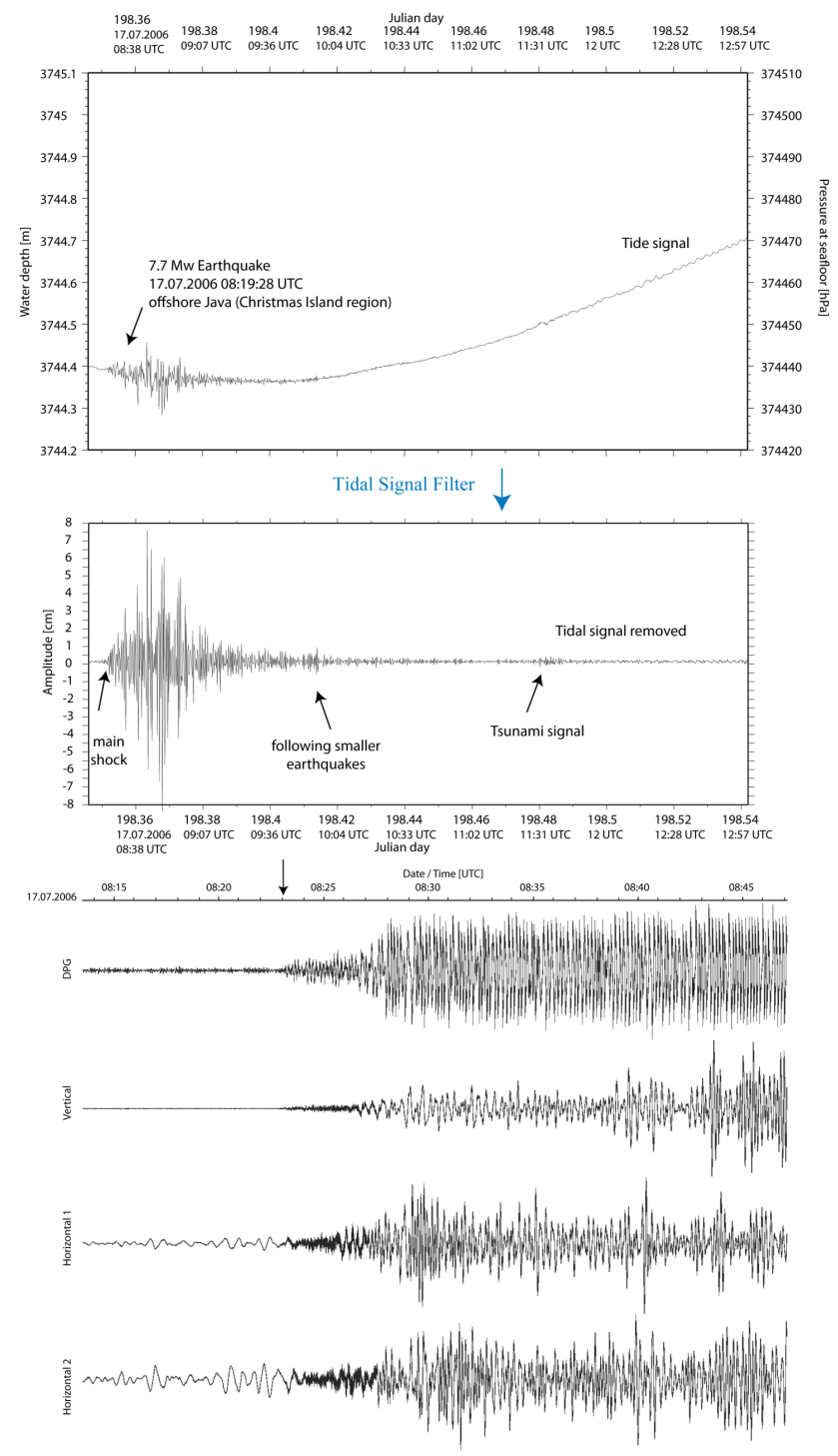

Fig. 22. Absolute pressure (top two), differential pressure gauge (DPG) and seismic (bottom four) data recorded by OBU-01-B located at $0^{\circ} 25.515^{\prime} \mathrm{S} / 96^{\circ} 51.658^{\prime} \mathrm{E}$ near mooring GITEWS-1 near Sumatra at $0^{\circ} 25.515^{\prime} \mathrm{S} / 96^{\circ} 51.658^{\prime} \mathrm{E}$, depicting the 17 July 2006 $\mathrm{Mw}=7.7$ earthquake. Data are high-pass frequency filtered. Arrow marks onset of P-wave arrival.

PACT deployments in Indonesia and the OBU tests in the Mediterranean. These first deployments now resulted in a set of field-tested, modem specific parameter settings to be used in future deployments. Furthermore, the HAM.node modems feature the option of an automatic, ambient noise depended adjustment of its modulation and coding schemes, which may be used in future to minimize energy demands while maintaining high acoustic transmission success rates.

The above results provide a proof-of-concept with regard to the use of PACT system as integral part of the GITEWS ocean instrumentation system. Three additional PACT-BU 
units have been built and their deployment is in planning. The experiences made during first embedded deployment let to system improvements which are expected to overcome the problems encountered. A yet unclear issue however, is the long term stability of the umbilical cord between the hosting buoy and the surface unit. First promising results of the OBUs support the expectation of a successful planned deployment and operation of three OBUs as part of the GITEWS infrastructure in the near future.

However, with PACT and OBU being the far-outpost of the GITEWS sensor infrastructure, their successful individual operation does not suffice. Rather, to be able to make use of the data provided by these instruments, the entire communication chain, including the hosting surface buoy, satellite communication and land-based infrastructure needs to operate and be maintained for extended periods of times. In addition, regular cruises are mandatory to maintain the deep-sea sensor array. It remains to be seen if the considerable efforts that are necessary to maintain the hosting deep-sea moorings and the respective ocean bottom instrument can be sustained on decadal time scales. Inevitably, the usability of the entire GITEWS effort now lasts in large part on a successful implementation of such administrative and logistic structures.

Acknowledgements. The GITEWS project (German Indonesian Tsunami Early Warning System) is carried out through a large group of scientists and engineers from the GFZ, German Research Centre for Geosciences (consortium leader) and its partners from the German Aerospace Center (DLR), the Alfred Wegener Institute for Polar and Marine Research (AWI), the GKSS Research Centre, the Konsortium Deutsche Meeresforschung (KDM), the Leibniz Institute for Marine Sciences (IFM-GEOMAR), the United Nations University (UNU), the Federal Institute for Geosciences and Natural Resources (BGR), the German Agency for Technical Cooperation (GTZ), as well as from Indonesian and other international partners. Funding is provided by the German Federal Ministry for Education and Research (BMBF), Grant 03TSU01.

The PACT project substantially benefited from the support and technical advice given by Erran Sousa, Gerald Chaplin and Randy Watts of the University of Rhode Island regarding technical details of the PIES and Gerrit Meinecke of MARUM who provided essential atsea test opportunities at the DOLAN mooring. Ingo Richter, Optimare Sensorsysteme AG, provided an essential contribution by creating the PACT daemon. Edith Davidis, Jens Schröter, and Jörn Behrens (all AWI) supported PACT throughout the projects funding period with regard to the the extensive administrative requirements of this multi-partner project. During the early phase of the project, Chris Meinig of NOAA provided invaluable support by explaining details of the DART ${ }^{\circledR}$ system. Last not least, we would like to thank an unknown Indonesian fisherman who retrieved the drifting PACTBU and brought the finding to the attention of Ade Edward at the West Sumatra Disaster Management Operation Control Centre in Padang, Sumatra, and Harald Spahn at Gesellschaft für Technische Zusammenarbeit (GTZ).

The OBU team especially likes to thank Jean-Francois Drogou and his colleagues from Ifremer, La Seyn-sur-mer for their enthusiastic help during our trials in the Mediterranean Sea. The authors also thank I. Nissen, W. Jans and co-workers from the FWG, Kiel for sharing their experience regarding the use and performance of acoustic modems.

NCEP reanalysis data was provided by the NOAA/OAR/ESRL PSD, Boulder, Colorado, USA, via their Web site at http://www.esrl.noaa.gov/psd/. The altimeter products were produced and distributed by Aviso (http://www.aviso.oceanobs.com/), as part of the SSALTO ground processing segment. Last but not least, the authors would like to thank the referees for their most insightful and constructive comments, which greatly helped improving the manuscript.

Edited by: U. Münch

Reviewed by: F. Gonzalez and another anonymous referee

\section{References}

Babeyko, A. Y., Hoechner, A., and Sobolev, S. V.: Source modeling and inversion with near real-time GPS: a GITEWS perspective for Indonesia, Nat. Hazards Earth Syst. Sci., 10, 1617-1627, doi:10.5194/nhess-10-1617-2010, 2010.

Behrens, J.: Advisory report on deep ocean wave gauges Overview: Tsunami Project Documentation Document No. 021, Alfred-Wegener-Institut für Polar- und Meeresforschung, Bremerhaven, 2008.

Behrens, J., Androsov, A., Babeyko, A. Y., Harig, S., Klaschka, F., and Mentrup, L.: A new multi-sensor approach to simulation assisted tsunami early warning, Nat. Hazards Earth Syst. Sci., 10, 1085-1100, doi:10.5194/nhess-10-1085-2010, 2010.

Benvenuto, N. and Cherubini, G.: Algorithms for Communications Systems and Their Applications, John Wiley \& Sons, 2002.

Bialas, J. and Flueh, E. R.: Ocean Bottom Seismometers, Sea Technol., 40(4), 41-46, 1999.

Böning, C., Boebel, O., and Klatt, O.: Transport variations of the Antarctic Circumpolar Current, in: The expedition of the research vessel "Polarstern" to the Antarctic in 2008 (ANTXXIV/3), Reports on polar and marine research, vol. 606, edited by: Fahrbach, E. and de Baar, H., pp. 65-71, Alfred Wegener Institute for Polar and Marine Research, Bremerhaven, 2010.

Chaplin, G. F. and Watts, D. R.: Inverted echo sounder development, paper presented at IEEE Oceans '84 Conf. Rec., Int. of Electr. and Electr. Eng., New York 1984.

Cox, C., Deaton, T., and Webb, S.: A deep-sea differential pressure gauge, J. Atmos. Oceanic Technol., 1(3), 237-246, 1984.

develogic GmbH: Technical Manual: User manual HAM.NODE Hydro Acoustic Modem with multi node capability, Rev. C3, develogic $\mathrm{GmbH}$, Hamburg, 2008.

Fleischer, J., Häner, R., Herrnkind, S., Kloth, A., Kriegel, U., Schwarting, H., and Wächter, J.: An integration platform for heterogeneous sensor systems in GITEWS - Tsunami Service Bus, Nat. Hazards Earth Syst. Sci., 10, 1239-1252, doi:10.5194/nhess-10-1239-2010, 2010.

Gennerich, H. H. and Villinger, H.: Long term ocean bottom pressure monitoring in the Logatchev hydrothermal field - indications for tremor, earthquakes, uplift and subsidence, paper presented at EGU2009-9889-2, EGU General Assembly 2009, 2009. 
Hanka, W., Saul, J., Weber, B., Becker, J., Fauzi, F., Harjadi, P., et al.: Real-time earthquake monitoring for tsunami warning in the Indian Ocean, Nat. Hazards Earth Syst. Sci., in review, 2010.

Harig, S., Chaeroni, C., Pranowo, W. S., and Behrens, J.: Tsunami simulations on several scales - Comparison of approaches with unstructured meshes and nested grids, Ocean Dynam., 58(5-6), 429-440, 2008.

Hasegawa, A., Horiuchi, S., and Umino, N.: Seismic structure of the northeastern Japan convergent margin - a synthesis, J. Geophys. Res., 99(B11), 22295-22311, 1994.

Husen, S., Kissling, E., Flueh, E., and Asch, G.: Accurate hypocenter determination in the shallow part of the Nazca subduction zone in Northern Chile using a combined on-/offshore network, Geophys. J. Int., 138, 687-701, 1999.

International Telecommunication Union, ITU-T Rec. X.200 (07/94) Information technology - Open Systems Interconnection - Basic reference model: The basic mode 59 pp, 1998.

Kalnay, E., Kanamitsu, M., Kistler, R., Collins, W., Deaven, D., Gandin, L., Iredell, M., Saha, S., White, G., Woollen, J., Zhu, Y., Chelliah, M., Ebisuzaki, W., Higgins, W., Janowiak, J., Mo, K. C., Ropelewski, C., Wang, J., Leetmaa, A., Reynolds, R., Jenne, R., and Joseph, D.: The NCEP/NCAR 40-Year Reanalysis Project, B. Am. Meteorol. Soc., 77(3), 437-470, 1996.

Kennelly, M.: Inverted Echo Sounders (IES/PIES/CPIES), http:// www.po.gso.uri.edu/dynamics/IES/index.html, 2009.

MARUM: DOLAN, http://www.marum.de/en/DOLAN.html, 2010.

Meinig, C., Stalin, S. E., Nakamura, A. I., González, F., and Milburn, H. G.: Technology developments in real-time tsunami measuring, monitoring and forecasting, paper presented at Oceans 2005 MTS/IEEE, Washington, D.C., 19-23 September 2005.
Meinig, C., Stalin, S. E., Nakamura, A. I., and Milburn, H. B.: System for reporting high resolution ocean pressures in near real time for the purposes of tsunami monitoring, United States Patent 7289907, 324 pp., 2007.

Mofjeld, H. O.: Tsunami detection algorithm, http://nctr.pmel.noaa. gov/tda_documentation.html, 1997.

OPTIMARE Sensorsysteme AG: Technical Manual: Operating manual Pressure Acoustic Coupled Tsunameter (PACT), Rev. 30 November 2008, OPTIMARE Sensorsysteme AG, Bremerhaven, 2008.

Rudloff, A., Lauterjung, J., Münch, U., and Tinti, S.: Preface "The GITEWS Project (German-Indonesian Tsunami Early Warning System)", Nat. Hazards Earth Syst. Sci., 9, 1381-1382, doi:10.5194/nhess-9-1381-2009, 2009.

Schöne, T., Subarya, C., Manurung, P., Noelte, C., Roemer, S., Galas, R., Illigner, J., Kloth, A., Koeppl, M., Queisser, T., Selke, C., Stolarczuk, N., and Bartsch, M.: Offshore and onshore sea level measurements, paper presented at Proceedings of the International Conference on Tsunami Warning (ICTW), Bali, Indonesia, 2008.

Schöne, T., Pandoe, W., Mudita, I., Roemer, S., Iligner, J., Zech, C., and Galas, R.: GPS water level measurements in Indonesia - Contribution to Indonesia's Tsunami Early Warning System, Nat. Hazards Earth Syst. Sci., in review, 2010.

Shu Lin and Costello, D. J.: Error Control Coding (2nd Edition), Prentice-Hall, 2004.

Tracey, K., Wimbush, M., and Watts, R.: PIES bibliography, http: //www.po.gso.uri.edu/dynamics/IES/iesbibupdated.pdf, 2009.

University of Rhode Island: Inverted Echo Sounder user's manual 6.2, 166 pp, University of Rhode Island, Narragansett, 2006.

USGS (United States Geological Survey): Earthquake Data Base; http://earthquake.usgs.gov/earthquakes/eqarchives/epic/, 2009. 